\title{
1 Microbiota mediated plasticity promotes thermal \\ 2 adaptation in Nematostella vectensis
}

4 Laura Baldassarre ${ }^{1,4}$, Hua Ying ${ }^{2}$, Adam Reitzel $^{3}$, Sebastian Fraune ${ }^{1 *}$

$6{ }^{1}$ Institute for Zoology und Organismic Interactions, Heinrich-Heine Universität 7 Düsseldorf, Germany;

$8{ }^{2}$ ANU Research School of Biology, The Australian National University, Canberra, 9 Australia;

$10{ }^{3}$ Biological Sciences, University of North Carolina at Charlotte, Charlotte, United 11 States;

$12{ }^{4}$ Istituto Nazionale di Oceanografia e di Geofisica Sperimentale - OGS, Sezione di 13 Oceanografia, Trieste, Italy.

$15{ }^{*}$ Corresponding author:

16 Prof. Dr. Sebastian Fraune

17 Heinrich-Heine Universität Düsseldorf

18 Institut für Zoologie und Organismische Interaktionen

19 Universitätsstraße 1

20 Gebäude: 26.12 Etage/Raum: 00.27

2140225 Düsseldorf

22 Tel.: +49 211 81-14991

23 Fax: +49 211 81-11971

24 Email: fraune(a)hhu.de

25 https://www.organismicinteractions.hhu.de/

27 Running title: Microbiota contribution to host thermal tolerance 


\section{Abstract}

30 At the current rate of climate change, it is unlikely that multicellular organisms will be 31 able to adapt to changing environmental conditions through genetic recombination 32 and natural selection alo. Thus, it is critical to understand alternative mechanisms 33 that allow organisms to cope with rapid environmental changes. Here, we used the 34 sea anemone Nematostella vectensis as model to investigate the microbiota as 35 putative source of rapid adaptation. Living in estuarine ecosystems, highly variable aquatic environments, $N$. vectensis has evolved the capability of surviving in a wide range of temperatures and salinities. In a long-term experiment, we acclimated polyps of Nematostella to low $\left(15^{\circ} \mathrm{C}\right)$, medium $\left(20^{\circ} \mathrm{C}\right)$ and high $\left(25^{\circ} \mathrm{C}\right)$ temperatures, in order to test the impact of microbiota-mediated plasticity on animal acclimation.

40 Using the same animal clonal line, propagated from a single polyp, allowed us to 41 eliminate effects of the host genotype. Interestingly, the higher thermal tolerance of animals acclimated to high temperature, could be transferred to non-acclimated animals through microbiota transplantation. In addition, offspring survival was highest from mothers acclimated to high temperature, indicating the transmission of thermal resistance to the next generation. Microbial community analyses of the F1 generation revealed the transmission of the acclimated microbiota to the next generation. These results indicate that microbiota plasticity can contribute to animal thermal acclimation and its transmission to the next generation may represent a rapid mechanism for thermal adaptation. 


\section{Introduction}

52 Changes in the climate are proceeding worldwide at a rate never registered before and temperatures will rise dramatically in the coming decades. Species able to migrate could move toward new-favourable areas, but those that have limited dispersal capacities or are sessile will have only two options: adaptation or extinction. Traditional theory and research since the Modern Synthesis have focused on the balance of mutation and selection as the central explanation for the adaptation of populations to their environment and as the generator of phenotypic novelty. However, some organisms also have a remarkable ability to acclimate to environmental change during their lifetime.

The mechanisms for acclimation are generally assumed to be due to shifts in gene expression regulation ${ }^{1,2}$. A focus on this factor alone is surely incomplete because the phenotype of an animal cannot be explained entirely by its genes. In 1927, the microbiologist Ivan E. Wallin hypothesized in his book, "Symbionticism and the Origin of Species", that the acquisition of bacterial endosymbionts favours the origin of new species ${ }^{3}$. Unlike the genes and regulatory regions of the genome, microbial composition can be rapidly modified by environmental cues, and may thus represent a mechanism for rapid acclimation and adaptions of individuals to a changing environment ${ }^{4-7}$. Recently, the microbiota-mediated transgenerational acclimatization (MMTA) concept was proposed ${ }^{8}$, suggesting that changes in microbiota assemblages, occurring in acclimating animals, may be passed on through generations to confer long-lasting resistance to changing environments by individuals and populations.

To be able to disentangle host genetic and microbial contributions to thermal acclimation, we took advantage of the model system Nematostella vectensis ${ }^{9} . \mathrm{N}$. vectensis, an anthozoan cnidarian, is a sedentary predator that resides exclusively in estuaries and brackish water environments, where it lives borrowed in sediments ${ }^{10}$. It is a wide-spread species that has been found in both Pacific and Atlantic coasts of the US and of the UK. In their natural habitats, wild populations of $N$. vectensis experience high variations of salinity, temperature and pollutants ${ }^{11-16}$. Under lab conditions, all the developmental stages are procurable on a weekly basis and spawning is induced by a shift in temperature and exposure to light ${ }^{17}$. N. vectensis can be easily cultured in high numbers ${ }^{13}$ and clonally propagated to eliminate 
85 vectensis harbors a specific microbiota whose composition changes in response to 86 different environmental conditions and among geographic locations ${ }^{18}$. Recently, has

87 been shown that female and male polyps transmit different bacterial species to the 88 offspring and that further symbionts are acquired from the environment during 89 development ${ }^{19}$. Furthermore, a protocol based on antibiotic-treatment was 90 established to generate germ-free animals that allow controlled recolonization 91 experiments to be conducted ${ }^{20}$. All together, these characteristics make the sea 92 anemone $N$. vectensis a uniquely informative model organism to investigate the 93 effects of bacterial plasticity on thermal acclimation ${ }^{5}$.

94 Here we used a clonal line of $N$. vectensis to characterise physiological and microbial 95 plasticity of the holobiont under different thermal conditions, while eliminating the 96 variability due to different host genotypes. Using microbial transplantations to non97 acclimated polyps, we proved the ability of acclimated microbes to confer resistance 98 to thermal stress. We further showed that thermal resistance to heat stress is 99 transmitted to the next generation.

100 Altogether, we provide strong evidences that microbiota-mediated plasticity

101 contributes to the adaptability of $N$. vectensis to high temperature and that the 102 transmission of acclimated microbiotas represents a mechanism for rapid adaptation. 


\section{Materials and methods}

\section{Animal culture}

107 All experiments were carried out with polyps of N. vectensis (Stephenson 1935). The 108 adult animals of the laboratory culture were F1 offspring of $\mathrm{CH} 2 \mathrm{XCH} 6$ individuals 109 collected from the Rhode River in Maryland, USA 13,17 They were kept under 110 constant, artificial conditions without substrate or light in plastic boxes filled with $1 \mathrm{~L}$ 111 ca. Nematostella Medium (NM), which was adjusted to $16 \%$ salinity with Red Sea 112 Salt $^{\circledR}$ and Millipore $\mathrm{H}_{2} \mathrm{O}$. Polyps were fed 2 times a week with first instar nauplius 113 larvae of Artemia salina as prey (Ocean Nutrition Micro Artemia Cysts 430 - 500 gr, 114 Coralsands, Wiesbaden, Germany) and washed once a week with media pre115 incubated at the relative culture temperatures.

\section{Animal acclimation}

118 A single female polyp from the standard laboratory culture conditions (16\% ppt, $11920^{\circ} \mathrm{C}$ ) was isolated and propagated via clonal reproduction. When a total of 150 new 120 clones was reached, they were split into 15 different boxes with 10 animals each.

121 The boxes were moved into 3 different incubators (5 boxes each) set at 15, 20 and $12225^{\circ} \mathrm{C}$ respectively and the animals were kept under constant culture regime as 123 described above. When the total of 50 polyps per box was reached, it was 124 maintained constant by manually removing the new clones formed. Every week the 125 number of new clones, dead and spontaneous spawning events where recorded.

\section{Dry weights}

128 Ten animals from each acclimation temperature (AT) were rinsed quickly in pure ethanol and placed singularly in $1.5 \mathrm{ml}$ tubes, previously weighted on an analytical scale. The animals were left dry at $80^{\circ} \mathrm{C}$ in a ventilated incubator for 4 hours. After complete evaporation of fluids, the animals with the tubes were weighed on the same analytical scale and the dry weight calculated.

\section{Generation of axenic polyps}

135 In order to reduce the total bacterial load and remove the most of associated bacteria 136 (axenic state), animals belonging to the same clonal line, were treated with an 137 antibiotic $(A B)$ cocktail of ampicillin, neomycin, rifampicin, spectinomycin and 
138 streptomycin (50 $\mu \mathrm{g} / \mathrm{ml}$ each) in filtered (on $0.2 \mu \mathrm{m}$ filter membrane), autoclaved NM

139 (modified from ${ }^{21}$ ). The polyps were incubated in the antibiotic cocktail for two weeks

140 in 50ml Falcon tubes (10 animals each). The medium and the antibiotics were

141 changed every day and the tubes 3 times per week. After the treatment the polyps

142 were incubated for 1 week in sterile NM without antibiotics to let them recover before

143 the recolonization. After the 2 weeks $A B$ treatment, the axenic state was checked by

144 smashing single polyps into $1 \mathrm{ml}$ sterile NM and by plating $100 \mu \mathrm{l}$ of the homogenate

145 on marine broth plates, successively incubated for 1 week at $20^{\circ} \mathrm{C}$. In addition, we

146 performed a PCR with primers specific for the V1-V2 region of the bacterial 16S

147 rRNA gene (27F and 338R). No CFUs on the plates and a weaker signal in the PCR

148 electrophoretic gel compared with wild-type controls were considered evidences of

149 bacteria reduction and axenic state of the animals.

\section{Bacteria transplantation}

152 For this experiment, the protocol for conventionalised recolonised Hydra polyps was

153 modified from ${ }^{21}$. For each AT, 100 axenic adult polyps were recolonised with the 154 supernatant of 10 acclimated adult polyps (2 polyps from each acclimated culture 155 box), singularly smashed in $5 \mathrm{ml}$ of sterile $\mathrm{NM}$. One $\mathrm{ml}$ of supernatant was added into 156 single Falcon tubes, containing 10 axenic animals each and filled with $50 \mathrm{ml}$ sterile 157 NM. At the recolonization time, additional animals from the original acclimated 158 cultures (1 polyp/box) were collected for DNA extraction and 16S sequencing. After 15924 hours, the medium was exchanged to remove tissue debris and non-associated 160 bacteria. One month after recolonization, the recolonised animals were tested for 161 heat stress tolerance as described above (in 3 rounds of 5 recolonized polyps for 162 each AT). At the time of HS, 15 recolonised polyps for each AT, were sampled for 163 DNA extraction and 16S sequencing.

Heat stress experiment (HS)

166 Adult polyps for each AT were placed singularly in 6-well plates and incubated at $16740^{\circ} \mathrm{C}$ for 6 hours (adapted from ${ }^{22}$ ). The day after, the number of survivors was 168 recorded and the mortality rate calculated.

\section{Sexual reproduction induction}


171 Animals separated singularly in 6-well plates, were induced for sexual reproduction

172 via light exposure for $10 \mathrm{~h}^{17}$ and temperature shift to $20^{\circ} \mathrm{C}$ for the animals acclimated

173 at $15^{\circ} \mathrm{C}$, and to $25^{\circ} \mathrm{C}$ for those acclimated at 20 and $25^{\circ} \mathrm{C}$. At each fertilization event,

174 sperm from a single induced male were pipetted directly onto each oocyte pack.

175 Fertilization was performed within 3 hours after spawning. The developing animals

176 were then cultured for 1 month under different temperatures $\left(15,20\right.$ or $\left.25^{\circ} \mathrm{C}\right)$.

178 Offspring survival test

179 Ten female polyps from each of the three ATs and one male polyp from the standard 180 culture conditions, were induced separately for spawning. After spawning the adult 181 polyps were removed and the oocyte packs fertilized as described above.

182 Fertilization was confirmed by observation under a binocular of the oocytes first 183 cleavages. After fertilization each oocyte pack was split with a scalpel in 3 parts that 184 were transferred into 3 distinct Petri dishes. The 3 oocyte pack sub-portions were 185 placed into 3 different incubators, set at 15,20 and $25^{\circ} \mathrm{C}$ respectively and let develop 186 for one month. Right after fertilization and after one month of development, pictures 187 of the oocytes and the juvenile polyps were acquired for successive counting through 188 ImageJ. Ratios between initial number of oocytes and survived juvenile polyps was 189 calculated and survival rate estimated.

\section{Bacteria vertical transmission test}

192 Five female polyps from each of the three ATs and one male polyp from the standard 193 conditions, were induced separately for spawning as described above. Immediately 194 after spawning the parental polyps were collected, frozen in liquid $\mathrm{N}$ and stored at $19580^{\circ} \mathrm{C}$ for successive DNA and RNA extraction. Five not induced female polyps from 196 each of the three ATs were also collected, frozen and stored for DNA extraction.

197 Oocyte packs were fertilised, split in 3 parts each and let develop for one month at 198 the three different developing temperatures (DTs), as described for the offspring 199 survival test. After one month of development, the juvenile polyps were collected, 200 frozen in liquid $\mathrm{N}$ and stored at $-80^{\circ} \mathrm{C}$. DNA was extracted from both the adults and 201 the offspring as described herein.

202

\section{DNA extraction}


204 DNA was extracted from adult polyps starving for 3 days before sacrifice and from

205 never fed juveniles. The recolonized animals were not fed for the whole duration of

206 the $A B$ treatment and the transplantation test (7 weeks in total). Animals were

207 washed two times with $2 \mathrm{ml}$ autoclaved $\mathrm{MQ}$, instantly frozen in liquid $\mathrm{N}$ without liquid

208 and stored at $-80^{\circ} \mathrm{C}$ until extraction. The gDNA was extracted from whole animals

209 with the DNeasy®Blood \& Tissue Kit (Qiagen, Hilden, Germany), as described in the

210 manufacturer's protocol. Elution was done in $50 \mu \mathrm{l}$ and the eluate was stored at

$211-80^{\circ} \mathrm{C}$ until sequencing. DNA concentration was measured by gel electrophoresis

212 (5 $\mu$ l sample on $1.2 \%$ agarose) and by spectrophotometry through Nanodrop 3300

213 (Thermo Fisher Scientific).

214

\section{RNA extraction}

216 Adult animals starved for 3 days before sacrifice. Polyps were washed two times with

$2172 \mathrm{ml}$ autoclaved $\mathrm{MQ}$, instantly frozen in liquid $\mathrm{N}$ without liquid and stored at $-80^{\circ} \mathrm{C}$

218 until extraction. Total RNA was extracted from the body column only, with the

219 AllPrep® DNA/RNA/miRNA Universal Kit (Qiagen, Hilden, Germany), as described in

220 the manufacturer's protocol. RNA elution was done in $20 \mu$ of RNAse-free water and

221 the eluates were stored at $-80^{\circ} \mathrm{C}$ until sequencing. RNA concentration was

222 measured through electrophoresis by loading $1 \mu$ of each sample on $1 \%$ agarose gel

223 and by spectrophotometry through Nanodrop 3300 (Thermo Fisher Scientific).

16S RNA sequencing and analysis

226 For each sample the hypervariable regions V1 and V2 of bacterial 16S rRNA genes

227 were amplified. The forward primer (5'-

228 AATGATACGgCGACCACCGAGATCTACAC XXXXXXXX TATGGTAATTGT

229 AGAGTTTGATCCTGGCTCAG-3') and reverse primer (5'-

230 CAAGCAGAAGACGGCATACGAGAT XXXXXXXX AGTCAGTCAGCC

231 TGCTGCCTCCCGTAGGAGT -3') contained the Illumina Adaptor (in bold) p5

232 (forward) and p7 (reverse) ${ }^{23}$. Both primers contain a unique 8 base index (index;

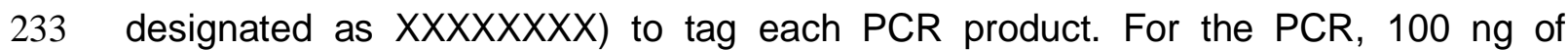

234 template DNA (measured with Qubit) were added to $25 \mu \mathrm{l}$ PCR reactions, which were

235 performed using Phusion ${ }^{\circledR}$ Hot Start II DNA Polymerase (Finnzymes, Espoo,

236 Finland). All dilutions were carried out using certified DNA-free PCR water (JT

237 Baker). PCRs were conducted with the following cycling conditions $\left(98^{\circ} \mathrm{C}-30 \mathrm{~s}, 30\right.$ 
$238 \times\left[98^{\circ} \mathrm{C}-9 \mathrm{~s}, 55^{\circ} \mathrm{C}-60 \mathrm{~s}, 72^{\circ} \mathrm{C}-90 \mathrm{~s}\right], 72^{\circ} \mathrm{C}-10 \mathrm{~min}$ ) and checked on a $1.5 \%$

239 agarose gel. The concentration of the amplicons was estimated using a Gel Doc TM

240 XR+ System coupled with Image Lab TM Software (BioRad, Hercules, CA USA) with

$2413 \mu \mathrm{l}$ of O'GeneRulerTM 100 bp Plus DNA Ladder (Thermo Fisher Scientific, Inc.,

242 Waltham, MA, USA) as the internal standard for band intensity measurement. The 243 samples of individual gels were pooled into approximately equimolar subpools as 244 indicated by band intensity and measured with the Qubit dsDNA br Assay Kit (Life 245 Technologies GmbH, Darmstadt, Germany). Subpools were mixed in an equimolar 246 fashion and stored at $-20{ }^{\circ} \mathrm{C}$ until sequencing. Sequencing was performed on the 247 Illumina MiSeq platform with v3 chemistry $(2 \times 300 \text { cycle kit })^{24}$. The raw data are 248 deposited at the Sequence Read Archive (SRA) and available under the project ID 249 PRJNA742683.

250 The 16S rRNA gene amplicon sequence analysis was conducted through the QIIME

$251 \quad 1.9 .0$ package ${ }^{25}$. Sequences with at least $97 \%$ identity were grouped into OTUs and 252 clustered against the QIIME reference sequence collection; any reads which did not 253 hit the references, were clustered de novo. OTUs with less than 50 reads were 254 removed from the dataset to avoid false positives which rely on the overall error rate 255 of the sequencing method ${ }^{26}$. Samples with less than 3600 sequences were also 256 removed from the dataset, being considered as outliers. For the successive analysis 257 the number of OTUs per sample was normalized to that of the sample with the lowest 258 number of reads after filtering.

259 Alpha-diversity was calculated using the Chao1 metric implemented in QIIME. Data 260 were subjected to descriptive analysis, and normality and homogeneity tests as 261 described herein. When normality, homogeneity and absence of significant outliers 262 assumptions were met; statistical significance was tested through one-way ANOVA. 263 When at least one of the assumptions was violated, the non-parametric Kruskal264 Wallis test was performed instead. When a significant difference between treatments 265 was stated, post-hoc comparisons were performed in order to infer its direction and 266 size effect.

267 Beta-diversity was calculated in QIIME according with the different $\beta$-diversity metrics 268 available (Binary-Pearson, Bray-Curtis, Pearson, Weighted-Unifrac and Unweighted269 Unifrac). Statistical values of clustering were calculated using the nonparametric 270 comparing categories methods Adonis and Anosim. 
271 Bacterial groups associated with specific conditions were identified by LEfSe

272 (http://huttenhower.sph.harvard.edu/galaxy) ${ }^{27}$. LEfSe uses the non-parametric

273 factorial Kruskal-Wallis sum-rank test to detect features with significant differential

274 abundance, with respect to the biological conditions of interest; subsequently LEfSe

275 uses Linear Discriminant Analysis (LDA) to estimate the effect size of each

276 differentially abundant feature.

277

278 Transcriptome analyses

279 The analysis was performed on five animals from each AT in two sequencing runs.

280 mRNA sequencing with previous poly-A selection was performed for 15 libraries on

281 the Illumina HiSeq 4000 platform, with 75bp and 150 bp paired-end sequencing

282 respectively. The quality of raw reads was assessed using FastQC v0.11.7

283 (Andrews, 2014). Trimmomatic v.0.38 ${ }^{28}$ was then applied to remove adaptors and

284 low-quality bases whose quality scores were less than 20 . Reads shorter than $50 \mathrm{bp}$

285 were removed, and only paired-end reads after trimming were retained. Reads were

286 mapped to the Ensembl metazoa Nematostella vectensis genome (release 40) using

287 the splice-aware aligner hisat2 v2.1.0 ${ }^{29}$ with rna-strandness RF option and default

288 parameters (Table S1).

289 RNA-seq data was used to improve the predicted $N$. vectensis gene model

290 downloaded from Ensembl Metazoa database release 40. Using mapped reads from

291 each temperature condition as input, StringTie v2.0 ${ }^{30}$ and Scallop v0.10.4 ${ }^{31}$ were

292 applied to perform genome guided transcriptome assemblies. The assembled

293 transcripts were subsequently compared and merged using TACO ${ }^{32}$. This produced

29442488 genes with 81163 transcripts, among which 21245 genes had significant

295 matches (blastx with parameter e-value $1^{\mathrm{e}-5}$ ) with proteins in the SwissProt database.

296 Assembled genes were compared with the Ensembl gene model using gffCompare

297 v0.11.2 ${ }^{33}$, from which genes with lower blastx e-value were selected. Ensembl genes

298 without matching assembled genes were retained, and assembled genes without

299 matching Ensembl genes but with significant matching SwissProt proteins were

300 added to the gene model. The final gene model included 20376 Ensembl genes,

3014400 improved genes and 2751 novel assembled genes (Table S2). The gene model

302 statistics and the completeness of gene models were assessed using BUSCO v3 ${ }^{34}$

303 on the Metazoa dataset that consisted of 978 core genes (Table S3). 
304 Total counts of read fragments aligned to the annotated gene regions were derived

305 using FeatureCounts program (Subread-2.0.0) ${ }^{35}$ with default parameters. Genes

306 whose combined counts from all samples were lower than 5 counts per million (cpm)

307 mapped reads were excluded from the analyses. Differential expression analyses

308 were performed in parallel using DESeq2 (v1.28.1) BioConductor package ${ }^{36}$, and

309 limma (voom v3.44.3) package ${ }^{37}$. Differentially expressed genes (DEGs, Table S4)

310 were determined based on False Discovery rate (FDR, Benjamini-Hochberg adjusted

311 p-value $\leq$ 0.05). Gene ontology annotation was derived from the best matching

312 SwissProt proteins. Enriched GO-terms in DEGs were identified by the topGO

313 (v2.40.0) BioConductor package (Table S5).

314

315 Results

316

317 Long-term acclimation at high temperature increases heat resistance in

318 Nematostella vectensis

319 Before starting the acclimation experiment, we propagated a single female polyp to

320150 clones and split these clones into 15 different cultures with 10 clonal animals

321 each, to ensure the same genotype in all acclimation regimes. We further propagated

322 these animals to 50 animals per culture and constantly maintained this number over

323 the course of the experiment. Subsequently, we aclimated these independent

324 cultures at low $\left(15^{\circ} \mathrm{C}\right)$, medium $\left(20^{\circ} \mathrm{C}\right)$ and high temperature $\left(25^{\circ} \mathrm{C}\right)$ (five cultures

325 each) for the period of 3 years (160 weeks) (Figure 1). 
327

328

329

330

331

332

333

334

335

336

337

338

339

340

341

342

343

344

345

346

347

348

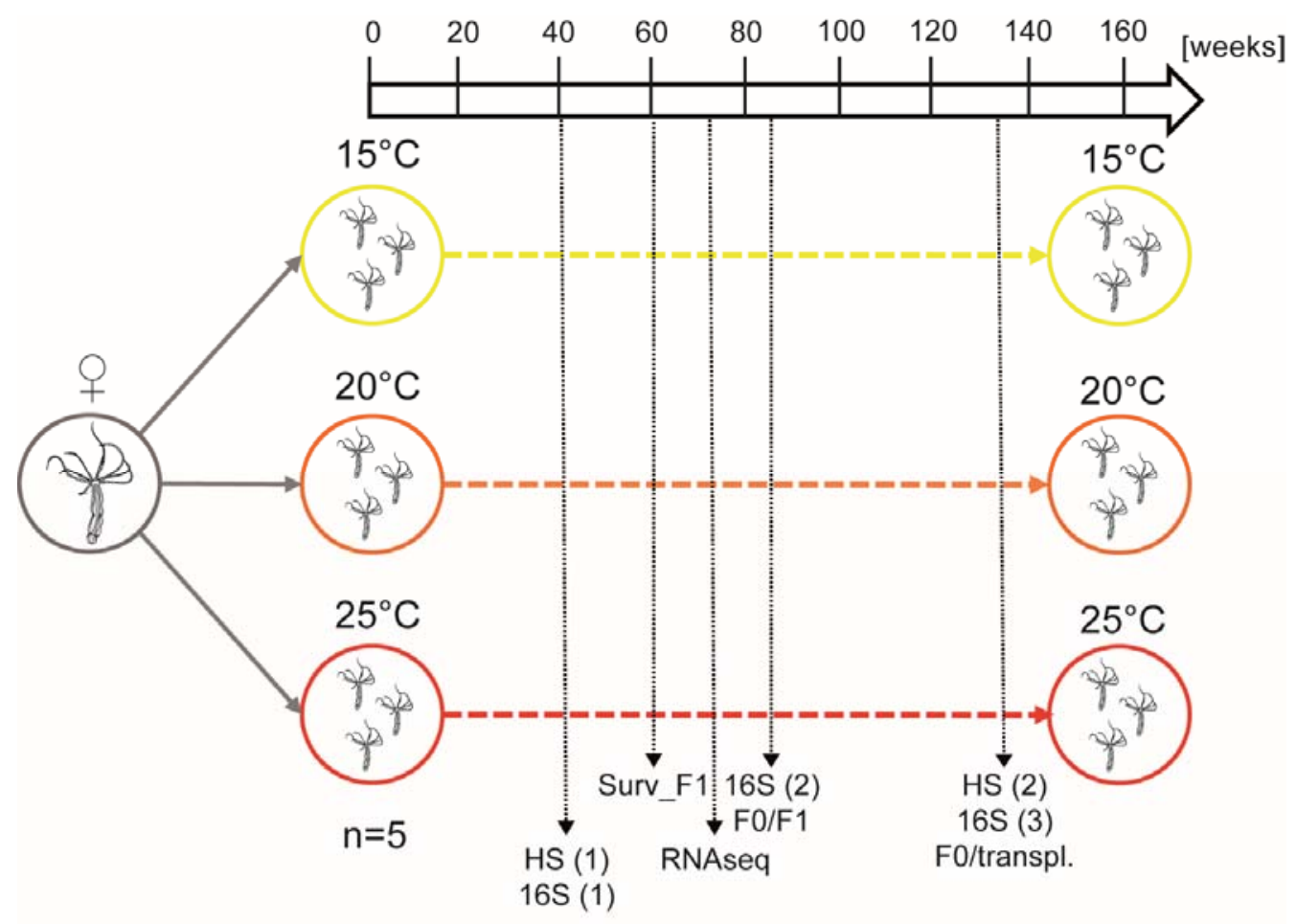

Figure 1. Experimental setup. A single female polyp from the standard culture conditions $(16 \%$ ppt, $20^{\circ} \mathrm{C}$ ) was isolated and propagated via clonal reproduction. When a total of 150 new clones was reached, they were split into 15 different culture boxes of 10 animals each. The boxes were put at three different acclimation temperature (AT) $\left(15,20\right.$ and $25^{\circ} \mathrm{C}, 5$ boxes each) and the number of animals/box was kept equal to 50 . Heat stress experiments (HS) $\left(6 \mathrm{~h}, 40^{\circ} \mathrm{C}\right)$ where performed at 40 and 132 weeks of acclimation (woa). Sexual reproduction was induced at 60 and 84 woa for the juveniles survival test (Surv_F1) and the bacteria vertical transmission test (F0/F1). At 40, 84 and 132 woa samples were collected for $16 \mathrm{~S}$ sequencing (16S); at 76 woa sampling for RNA sequencing was performed.

After 40 weeks of acclimation (woa), we tested, for the first time, the heat tolerance of acclimated polyps as a proxy for acclimation. We individually incubated polyps of each acclimated culture in ten replicates for 6 hours at $40^{\circ} \mathrm{C}$ and recorded their mortality (Figure 2-A). Already after 40 woa, significant differences in the mortality rates of clonal animals were detectable. While all animals acclimated to low temperature died after the heat stress, animals acclimated at $20^{\circ} \mathrm{C}$ and $25^{\circ} \mathrm{C}$ showed a significantly higher survival rate of $70 \%$ and $30 \%$, respectively (Figure 2-A). We repeated the measurement of heat tolerance two years later (132 woa). Interestingly, we observed a drastic increase in fitness in animals acclimated at high temperature, while the animals acclimated at $15^{\circ} \mathrm{C}$ and $20^{\circ} \mathrm{C}$ showed $100 \%$ mortality (Figure 2-A). (1) 
349

350

351

352

353

354

355

356

357

358

359

360

361

362

363

364

365

366

367

368

369

370

371

372

373

374

375

376
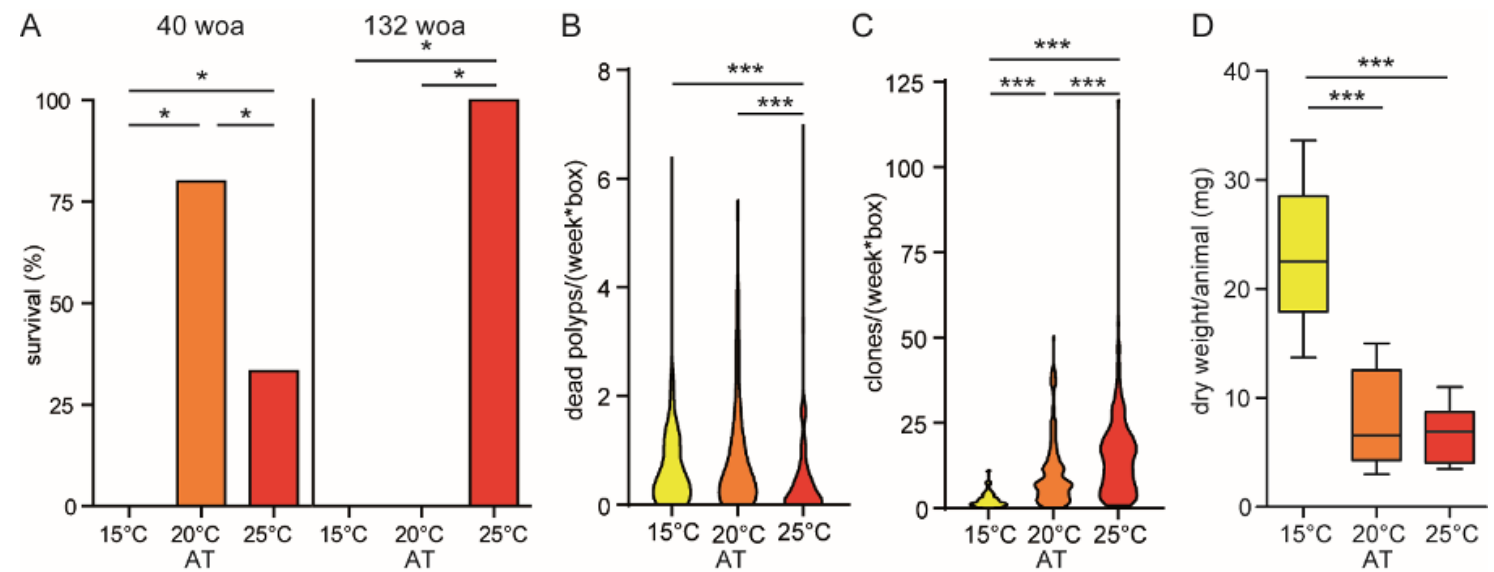

Figure 2. Phenotypic plasticity in response to thermal acclimation. (A) Survival of acclimated polyps after heat stress $\left(40^{\circ} \mathrm{C}, 6 \mathrm{~h}\right)$. Statistical analyses was performed by a Fisher's exact test $(n=10$ (40 woa), $n=5$ (132 woa)). (B) Average of dead polyps per week and box over the course of the experiment (E) Average of clones generated per week per 50 animals over the course of the experiment. (D) Dry weights of acclimated polyps at the end of the experiment (170 woa) $(n=10)$ : Statistical analyses in B, C and D were performed by one-way ANOVA followed by Tukey's post-hoc comparisons $\left({ }^{*}=p \leq 0.05,{ }^{* *}=p \leq 0.01,{ }^{* * *}=p \leq 0.001\right)$.

We also monitored the mortality rate in the acclimated cultures over the course of the experiment (Figure 2-B). While the mortality in cultures acclimated at $15^{\circ} \mathrm{C}$ and $20^{\circ} \mathrm{C}$ was below 0.5 polyps per week, the mortality rate at $25^{\circ} \mathrm{C}$ was significantly reduced in cultures acclimated at $25^{\circ} \mathrm{C}$. An additional phenotypic difference between the acclimated animals was the clonal growth, as animals acclimated at $25^{\circ} \mathrm{C}$ propagated asexually nearly seven times more than animals acclimated at $15^{\circ} \mathrm{C}$ (Figure 2-C).

This may explain the differences in body size, where animals acclimated at $15^{\circ} \mathrm{C}$ were more than three times bigger than the animals acclimated at 20 and $25^{\circ} \mathrm{C}$ (Figure 2-D). The different ATs affected also the fecundity of the animals: the polyps acclimated at the high ATs showed a significantly higher number of spontaneous spawning events recorded along the whole course of the experiment, compared with the $15^{\circ} \mathrm{C}$ acclimated animals that never spawned if not artificially induced (Figure S1).

These results indicate that $N$. vectensis possesses remarkable plasticity at long-term temperature acclimation realized through differences in thermal tolerance, body size, asexual propagation and fecundity. In the following, we analysed the associated microbiota and host transcriptomic responses as a source of thermal acclimation in N. vectensis. 
378 To monitor the dynamic changes in the associated microbiotas of acclimated 379 animals, we sampled single polyps from each of the 15 clonal cultures at 40, 84 and 380132 woa and compared their associated microbiota by 16S rRNA sequencing

381 (Figure 1). To determine the impact of AT and sampling time point on the 382 assemblage of the bacterial community, we performed principal coordinates analysis 383 (PCoA) (Figure 3-A and B).
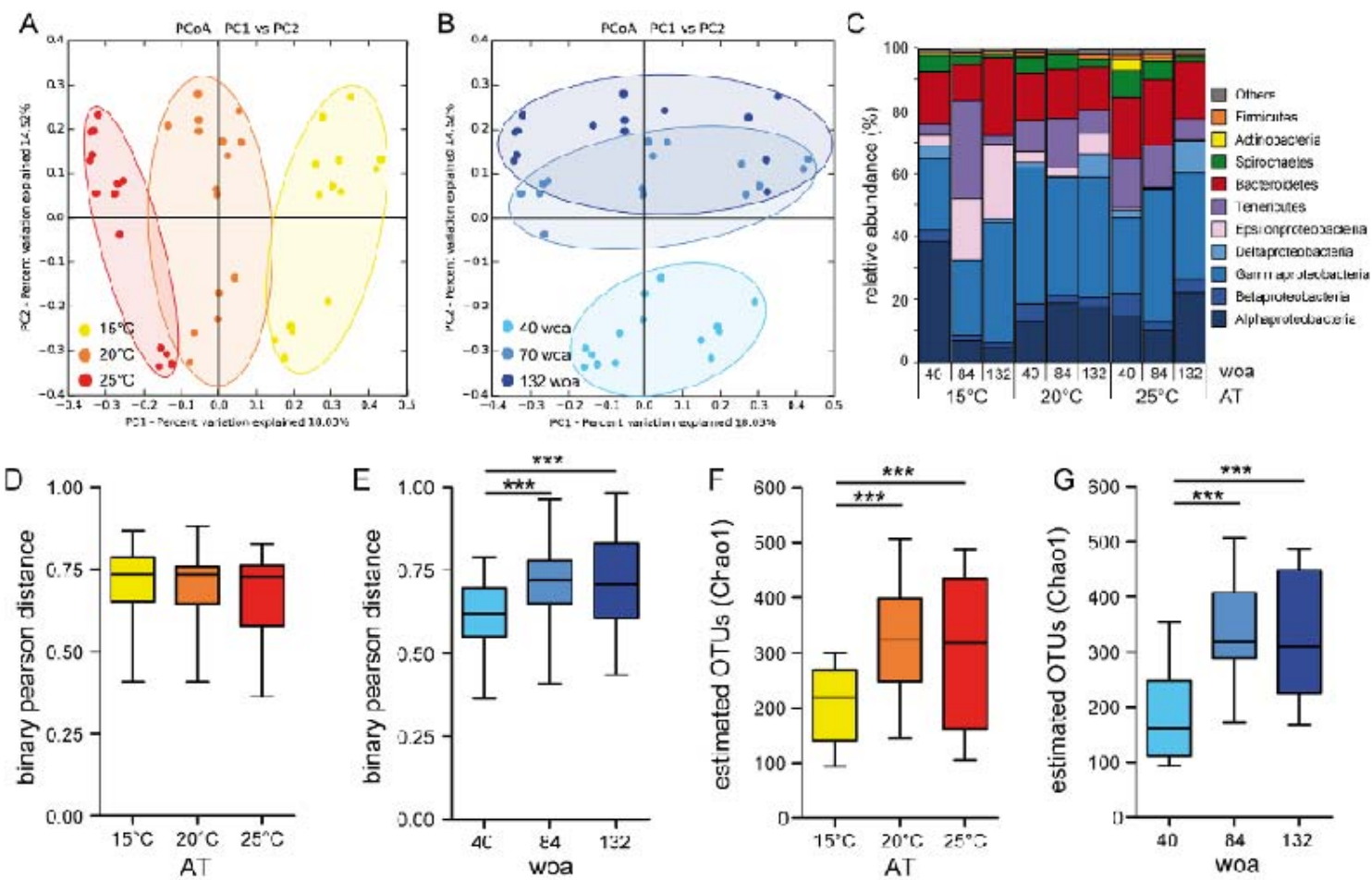

Figure 3. Bacterial community changes in response to thermal acclimation. (A) PCoA (based on binary-pearson metric, sampling depth $=3600$ ) illustrating similarity of bacterial communities based on AT. (B) PCoA (based on pinary-pearson metric, sampling depth $=3600$ ) illustrating similarity of bacterial communities based on woa. (C) Relative abundances of principal bacterial groups, the abundances were summarized under the relative higher taxonomic categories (classes and phyla) and reported as percentages of the total. (D) $\beta$-diversity distances within each AT (E) $\beta$-diversity distances within woa. Statistical analyses were performed using a non-parametric Kruskal-Wallis test followed by Dunn's post hoc comparisons ( $\left.p \leq 0.01^{* *}, p \leq 0.001^{* * *}\right)$. (F) a-diversity (Chao1) comparison by AT (max rarefaction depth $=3600(\mathrm{G})$ a-diversity (Chao1) comparison by woa (max rarefaction depth $=$ 3600), statistical analyses was performed by using one-way ANOVA followed by Tukey's post hoc comparisons $\left(p \leq 0.01^{* *}, p \leq 0.001^{* * *}\right)$.

While principal component 1 (PC1) mostly separates samples according to the AT (Figure 3-A), PC2 correlates with the different sampling time points (Figure 3-B). Using five different $\beta$-diversity metrics, we found that bacterial colonization is significantly influenced by both AT and sampling time point (Table 1). 
402

403

404

405

406

407

408

409

410

411

412

413

414

415

416

417

418

419

420

421

422

423

424

425

426

Table 1. Statistical analysis determining influence of AT and woa on the bacterial colonization. (number of permutations $=999$ ).

\begin{tabular}{llcccc} 
& & \multicolumn{2}{c}{ Adonis } & \multicolumn{2}{c}{ Anosim } \\
\cline { 3 - 6 } parameter & beta-diversity metric & $\boldsymbol{R 2}$ & $\boldsymbol{P}$ value & $\boldsymbol{R}$ & $\boldsymbol{P}$ value \\
\hline \multirow{3}{*}{ AT } & Binary-Pearson & 0.208 & 0.001 & 0.544 & 0.001 \\
& Bray-Curtis & 0.219 & 0.001 & 0.466 & 0.001 \\
& Pearson & 0.256 & 0.001 & 0.360 & 0.001 \\
& Weighted-Unifrac & 0.147 & 0.001 & 0.238 & 0.001 \\
woa & Unweighted-Unifrac & 0.193 & 0.001 & 0.521 & 0.001 \\
& Binary-Pearson & 0.230 & 0.001 & 0.608 & 0.001 \\
& Bray-Curtis & 0.199 & 0.001 & 0.372 & 0.001 \\
& Pearson & 0.217 & 0.001 & 0.277 & 0.001 \\
& Weighted-Unifrac & 0.149 & 0.001 & 0.173 & 0.001 \\
& Unweighted-Unifrac & 0.192 & 0.001 & 0.498 & 0.001 \\
\hline
\end{tabular}

Assigning the different microbial communities by the sampling time points revealed a shared clustering after 84 and 132 weeks of acclimation (woa) (Figure 3-B), suggesting a stabilization within the microbial communities after around 2 years of acclimation. In contrast, assigning the samples by AT revealed a clear clustering of the microbial communities (Figure 3-A) with the bacterial communities acclimated at $20^{\circ} \mathrm{C}$ clustering between the two extremes $\left(15^{\circ} \mathrm{C}\right.$ and $\left.25^{\circ} \mathrm{C}\right)$. This indicates that the three different ATs induced differentiation of three distinct microbial communities since the beginning of the acclimation process and that this differentiation is more severe between the extreme ATs. While most bacterial groups maintain a stable association with $N$. vectensis (Figure $\mathbf{3}-\mathbf{C}$ ), bacteria that contribute to the differentiation at the end of the acclimation process, are Alphaproteobacteria, that significantly increase at high temperature (Two-way ANOVA, $p<0.01$ ) and Epsilonproteobacteria, that significantly increase at low temperature (two-way ANOVA, p<0.001) (Figure 3-C).

Using the Binary-Pearson distance matrix, we calculated the distances between samples within all three acclimation regimes (Figure 3-D) and sampling time points (Figure 3-E). Continuous acclimation under the different temperature regimes revealed no differences in the within-treatment distances (Figure 3-D), indicating a similar microbial plasticity at all three ATs. In contrast, Binary-Pearson distances of the different sampling time points significantly increased between 40 and 84 woa (Figure 3-E) and stabilized between 84 and 132 woa. Interestingly, the a-diversity of bacteria associated with acclimated polyps was significantly higher at 20 and $25^{\circ} \mathrm{C}$, 
427 compared to those associated with polyps acclimated at $15^{\circ} \mathrm{C}$ (Figure 3-F). As for

428 the $\beta$-diversity, the $\alpha$-diversity was significantly increasing within the first 84 woa and

429 stabilized between 84 and 132 woa (Figure 3-G).

430 Altogether, these results show that the microbiota of $N$. vectensis reacts plastically to

431 environmental changes. The microbial composition changes stabilize within two

432 years of acclimation indicating a new homeostatic bacterial colonization status.

\section{Thermal acclimation induces a robust tuning of host transcriptomic profiles}

435 To evaluate the contribution of host transcriptional changes to the observed 436 increased thermal tolerance in animals acclimated at high temperature, we analysed 437 gene expression profiles of $N$. vectensis after 75 woa (Figure 1). We sampled from 438 each replicate culture one animal, extracted its mRNA and sequenced it by Illumina 439 HiSeq 4000 . The constant acclimation at 15,20 and $25^{\circ} \mathrm{C}$ induced a robust tuning of 440 the host transcriptomic profiles (Figure 4-A).

A

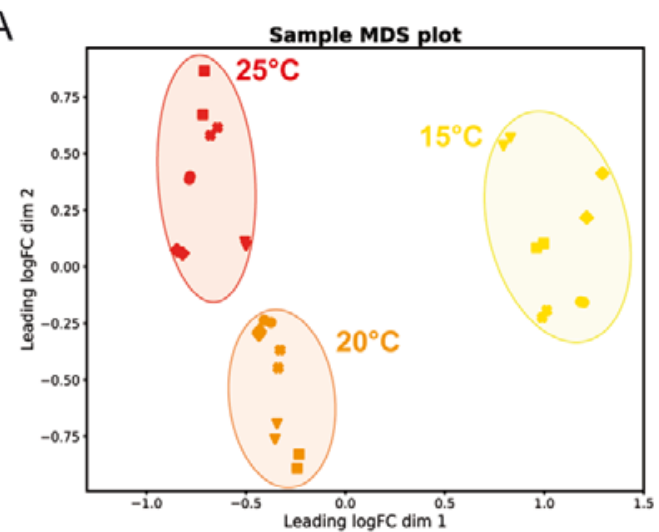

$\mathrm{B}$

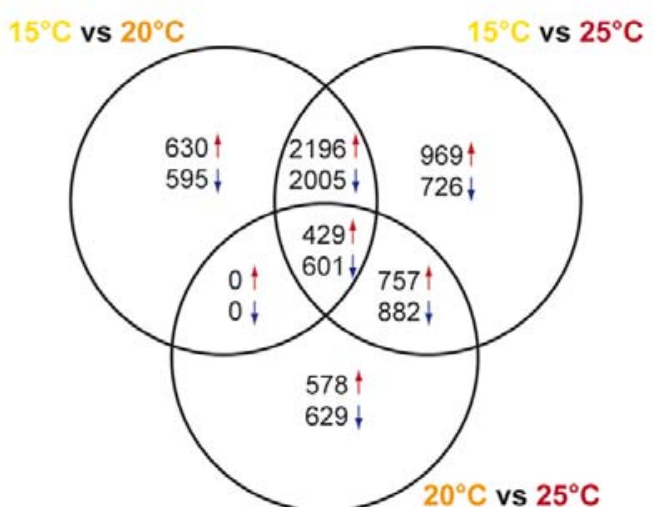

C

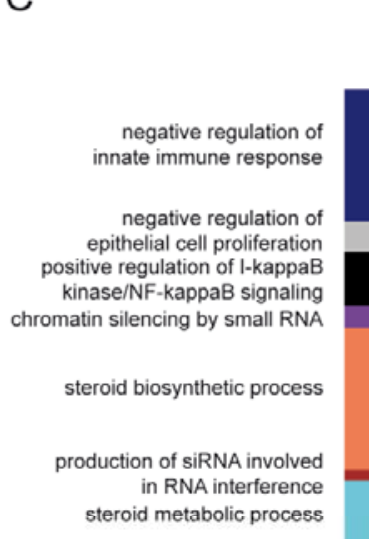

extracellular matrix organization

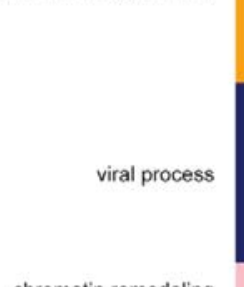

chromatin remodeling

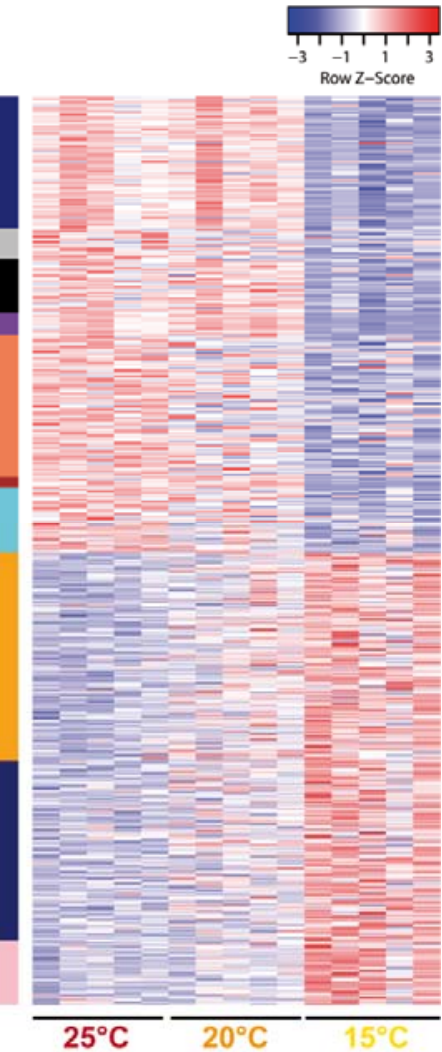

442

443

444

445
Figure 4. Host transcriptome changes after thermal acclimation. (A) MDS plot showing the clustering of the transcriptome samples according to the AT of the acclimated animals (samples were sequenced in technical replicates, indicated by the different symbols) (B) Venn diagram showing the differentially expressed genes within the three ATs pairwise comparisons. (C) Heat-map of 
differentially expressed genes in enriched GO term categories significantly enriched in the comparison between 15 and $25^{\circ} \mathrm{C}$ acclimated polyps.

In pairwise comparisons, we determined the differentially expressed (DE) genes (Figure 4-B) in all acclimated animals. While the comparison of transcriptomic profiles from polyps acclimated at 15 and $25^{\circ} \mathrm{C}$ revealed the highest number of $\mathrm{DE}$ genes, the comparison of 20 and $25^{\circ} \mathrm{C}$ acclimated animals revealed the lowest number of DE genes. In all three comparisons, we observed a similar fraction of upand down-regulated DE genes (Figure 4-B).

To retrieve potential molecular processes and signalling pathways enriched at the different ATs, we performed a gene ontology (GO) enrichment analysis and concentrated on GO categories significantly enriched in the comparison between 15 and $25^{\circ} \mathrm{C}$ acclimated polyps (Figure 4-C, Table S3). Animals acclimated to high temperature significantly increased expression in genes involved in innate immunity, gene regulation, epithelial cells proliferation, steroid biosynthesis and metabolism (Figure 4-C, Table S5). While genes associated with enriched GO categories show opposite expression levels at $15^{\circ} \mathrm{C}$ and $25^{\circ} \mathrm{C}$, an intermediate expression level was evident in the animals acclimated at $20^{\circ} \mathrm{C}$ (Figure 4-C). The animals acclimated to low temperature showed upregulation of genes associated with viral processes, which seems to be compatible with their general lower viability.

\section{Transplantation of acclimated microbiota induces differences in heat tolerance}

To disentangle the effects of transcriptomic and bacterial adjustments on thermal tolerance of acclimated polyps, we performed microbial transplantation experiments. We generated axenic non-acclimated animals and recolonized these animals with the microbiota of long-term acclimated polyps from the same clonal line. We smashed acclimated animals and used these suspensions, containing the acclimated microbiota, for the recolonization of axenic animals. We maintained microbiotatransplanted animals for one month at $20^{\circ} \mathrm{C}$ to allow the adjustment of a stable colonization.

To evaluate the success of bacteria transplantation, we performed 16S rRNA gene sequencing of 45 recolonized animals. PCoA analysis revealed that the transplanted microbiota cluster according to the acclimated source microbiota one month after transplantation (Figure 5-A, Table 2). 
481

482

483

484

485

486

487

488

489

490

491

492

493

494

495

496

497

498

499

500

501

502
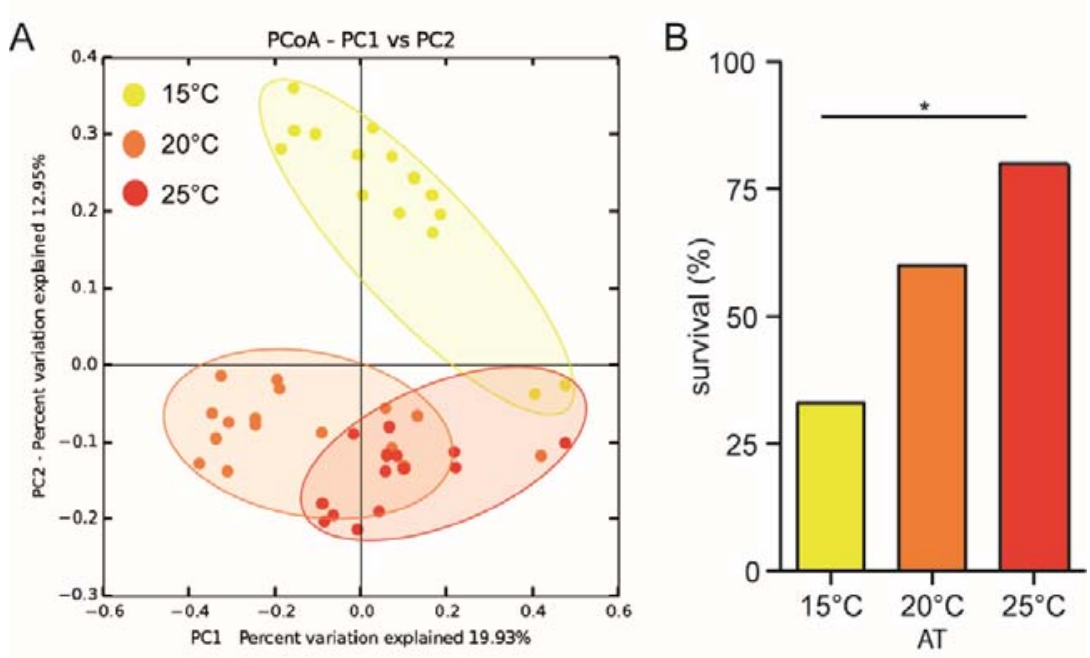

Figure 5. Transplantation of acclimated microbiota confers thermal resistance. (A) PCoA (based on binary-pearson metric, sampling depth $=3600$ ) illustrating similarity of transplanted bacterial communities based on AT of source microbiota (B) Heat stress survival of polyps recolonized with microbiota of acclimated animals. Statistical analyses were performed by pairwise Fisher's exact test $\left(\mathrm{n}=15,{ }^{*} \mathrm{p}=0.025\right.$.

Subsequently we tested the microbiota-transplanted animals for their heat tolerance as previously performed for the acclimated animals. The recolonized animals showed clear differences in mortality depending on the microbial source used for transplantation. A significant gradient in survival was evident from the animals recolonized with the $15^{\circ} \mathrm{C}$-acclimated microbiota (33\%) to those recolonized with the $25^{\circ} \mathrm{C}$-acclimated microbiota (80\%) (Figure 5-B). The animals transplanted with the $20^{\circ} \mathrm{C}$-acclimated microbiota showed an intermediate survival $(60 \%)$.

These results indicate that the high thermal tolerance of animals acclimated to high temperature can be transferred to non-acclimated animals by microbiota transplantation alone. Therefore, we conclude, that microbiota-mediated plasticity provides a rapid mechanism for a metaorganism to cope with environmental changes.

Table 2. Statistical analysis determining influence of AT of source microbiota on bacterial colonization (number of permutations $=999$ ).

\begin{tabular}{llcccc} 
& & \multicolumn{2}{c}{ Adonis } & \multicolumn{2}{c}{ Anosim } \\
\cline { 3 - 6 } parameter & beta-diversity metric & $\boldsymbol{R 2}$ & $\boldsymbol{P}$ value & $\boldsymbol{R}$ & $\boldsymbol{P}$ value \\
\hline \multirow{3}{*}{ AT of source microbiota } & Binary-Pearson & 0.199 & 0.001 & 0.486 & 0.001 \\
& Bray-Curtis & 0.183 & 0.001 & 0.346 & 0.001 \\
& Pearson & 0.165 & 0.001 & 0.194 & 0.001 \\
& Weighted-Unifrac & 0.161 & 0.001 & 0.272 & 0.001 \\
& Unweighted-Unifrac & 0.184 & 0.001 & 0.416 & 0.001 \\
\hline
\end{tabular}


504 Through the LEfSe analysis, we were able to detect bacterial OTUs differentially

505 represented between the polyps acclimated at 15 and $25^{\circ} \mathrm{C}$, and in the

506 corresponding transplanted animals (Table S6). These bacteria belong to the

507 families Phycisphaeraceae, Flavobacteriaceae, Emcibacteraceae,

508 Rhodobacteraceae, Methylophilaceae, Francisellaceae, Oceanospirillaceae and

509 Vibrionaceae, which are known to include various commensals, symbionts and

510 pathogens of marine organisms. Therefore, the OTUs overrepresented in the $25^{\circ} \mathrm{C}$

511 microbiota may constitute good candidates for providing thermal resistance to their

512 host.

513

514 Acclimated microbiota and thermal tolerance are transmitted to next 515 generation

516 In a next step, we tested if the acclimated microbiota influencing adults' thermal 517 tolerance is also affecting thermal tolerance of the offspring. Therefore, ten female

518 polyps from each long-term acclimated culture and one non-acclimated male polyp

519 were induced separately for spawning. All oocyte packs were fertilized with the 520 sperm of the same male polyp, split into three parts, counted and let develop for one 521 month at the three different temperatures (developing temperature - DT) in a full 522 factorial design (Figure 6-A).

523 
A

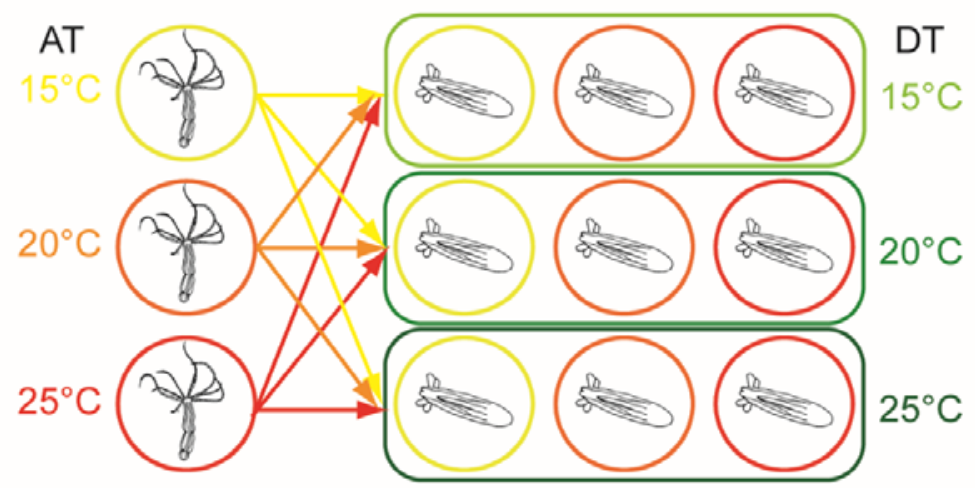

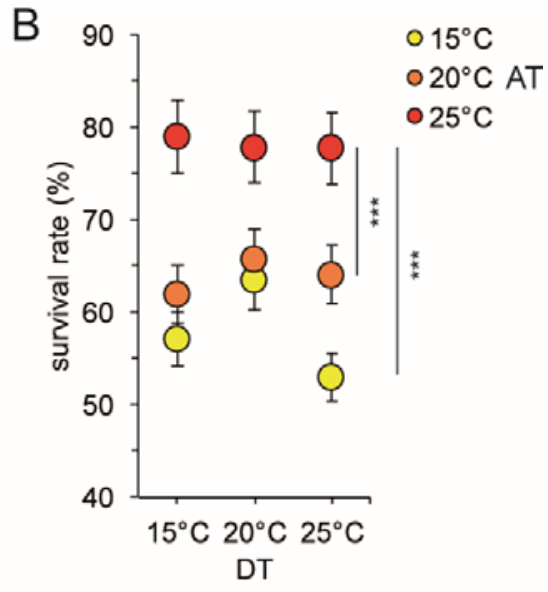

D

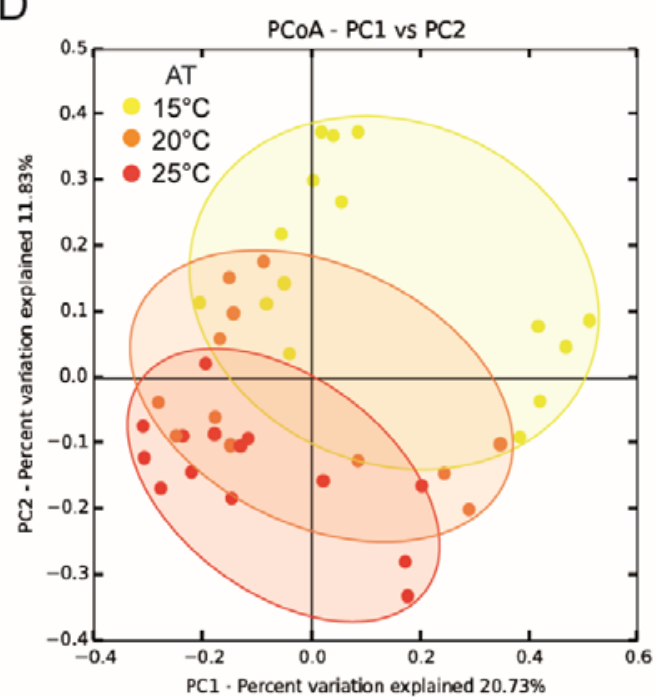

1. Percent variation explained $20.73 \%$
C

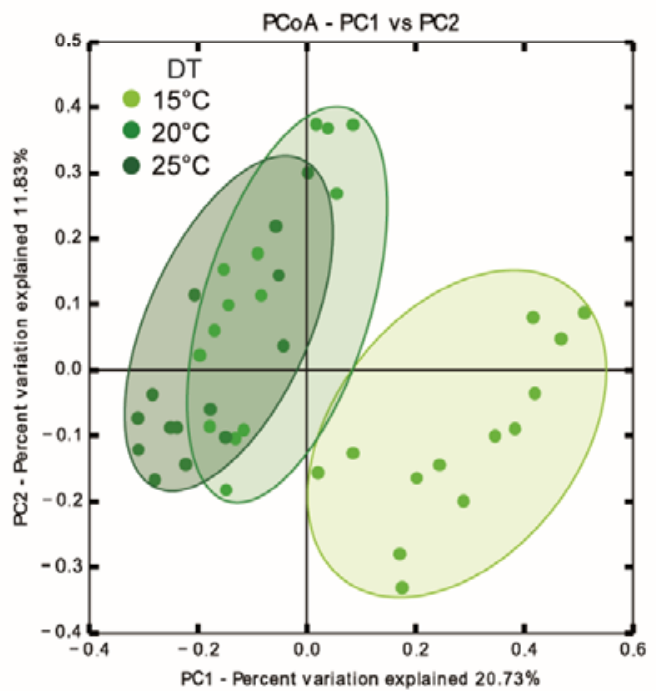

Figure 6. Transmission of thermal tolerance to the offspring. (A) Experimental scheme: acclimated females from each AT were induced for sexual reproduction. All oocyte-packs were fertilized with the sperms from a single male polyp from the standard conditions. After fertilization, each embryo-pack was split in 3 parts and placed at different DT $\left(15,20\right.$ or $\left.25^{\circ} \mathrm{C}\right)$. After one month of development, survival rate and bacterial colonisation were analysed. (B) Offspring survival rate (ratio between initial number of oocytes and survived juveniles polyps were calculated), a Kruskal-Wallis test was performed followed by Dunn's post-hoc comparisons $\left(n=10\right.$; $\left.{ }^{* * *} p \leq 0.001\right)$. (C) PCoA (based on Binary-Pearson metric, sampling depth $=24500$ ) illustrating similarity of bacterial communities according with offspring DT, (D) PCoA (based on Binary-Pearson metric, sampling depth $=24500$ ) illustrating similarity of bacterial communities according with mothers' AT.

After one month of development, the survived juvenile polyps were counted and corresponding survival rates were calculated (Figure 6-B). The offspring from the mothers acclimated at $25^{\circ} \mathrm{C}$ showed a significant higher overall survival rate compared to the offspring from polyps acclimated at medium and low temperature. In contrast, the offspring of polyps acclimated at $15^{\circ} \mathrm{C}$ showed the lowest survival rate at $25^{\circ} \mathrm{C}$ DT (Figure 6-B). In a second step, the juvenile polyps were subjected to $16 \mathrm{~S}$ rRNA sequencing to evaluate the transmission of acclimated microbes to the next 
544 generation. PCoA revealed a significant clustering of samples according to both DT

545 of the juveniles and AT of mother polyps (Figure 6-C and D, Table 3). While, on

546 average, around $50 \%$ of bacterial variation can be explained by the DT of the juvenile

547 polyps, around $20 \%$ of the bacterial colonization in juveniles can be explained by the

548 acclimation temperature of the mother polyps (Table 3).

549

550 Table 3. Statistical analysis determining influence of mothers' AT and offspring DT on bacterial 551 colonization of F1 generation polyps (number of permutations = 999).

\begin{tabular}{llcccc} 
& & \multicolumn{2}{c}{ Adonis } & \multicolumn{2}{c}{ Anosim } \\
\cline { 3 - 6 } parameter & beta-diversity metric & $\boldsymbol{R} 2$ & $\boldsymbol{P}$ value & $\boldsymbol{R}$ & $\boldsymbol{P}$ value \\
\hline \multirow{3}{*}{ AT of mother polyps } & & & & 0.373 & 0.001 \\
& Binary-Pearson & 0.170 & 0.001 & 0.237 & 0.001 \\
& Bray-Curtis & 0.133 & 0.001 & 0.166 & 0.002 \\
& Pearson & 0.139 & 0.001 & 0.091 & 0.010 \\
& Weighted-Unifrac & 0.093 & 0.024 & 0.005 \\
\hline Unweighted-Unifrac & 0.116 & 0.001 & 0.148 & 0.005 \\
& Binary-Pearson & 0.262 & 0.001 & 0.696 & 0.001 \\
& Bray-Curtis & 0.260 & 0.001 & 0.621 & 0.001 \\
& Pearson & 0.338 & 0.001 & 0.542 & 0.001 \\
& Weighted-Unifrac & 0.300 & 0.001 & 0.408 & 0.001 \\
& Unweighted-Unifrac & 0.211 & 0.001 & 0.413 & 0.001 \\
\hline
\end{tabular}

552

553 These results demonstrate that the acquired thermal tolerance in the maternal

554 generation is transmitted to the next generation. The fact that also parts of the

555 acclimated microbiota is transmitted and persisting in the juvenile $F 1$ polyps suggests

556 that vertically transmitted acclimated bacteria can be adaptive to high temperature. 


\section{Discussion}

\section{Long-term acclimation promotes heat tolerance in $\mathbf{N}$. vectensis}

561 The ability for marine animals to adapt to future thermal scenarios is of pivotal

562 importance for the maintenance of biodiversity and ecosystem functioning. Recent

563 studies indicate that sessile marine animals, like corals, sponges or anemones, could

564 adapt more rapidly than expected to climate change ${ }^{2,38-42}$. Recent and long-term

565 observations in the field displayed higher heat tolerance of corals pre-exposed to

566 thermal stress compared to unexposed ones and showed that wild populations are

567 slowly becoming less sensitive than they were in the past ${ }^{43-45}$. In our study, the

568 host's thermal resistance showed an increase along with the acclimation time. It is

569 important to point out that the standard culture temperature for $N$. vectensis in the lab

570 is $20^{\circ} \mathrm{C}$. The animals maintained at $20^{\circ} \mathrm{C}$, therefore, have been acclimated to this

571 condition for a long time and this might explain their highest survival at 40 woa.

572 Interestingly, the animals acclimated at $15^{\circ} \mathrm{C}$ showed at both time points $100 \%$

573 mortality, indicating that these animals would not be able to survive extreme

574 temperature events. Our results are consistent with other studies that investigated

575 the acclimation capacity of corals in lab experiments. Pre-acclimated individuals of

576 Acropora pruinosa, a scleractinian coral, did not bleach when exposed to successive

577 heat stress ${ }^{42}$. Also in the field, Acropora hyacinthus showed less mortality after heat

578 stress when acclimated to wide temperature fluctuations, than when acclimated to

579 less variable environments ${ }^{46}$. These different resistances are correlated to an

580 adaptive plasticity in the expression of environmental stress response (ESR) genes ${ }^{47}$

581 and the presence of an advantageous microbiota ${ }^{48}$, but a causative relation was not

582 shown in both cases. In our study, we disentangled the contribution of host gene

583 expression and microbiota to temperature acclimation in cnidarian, by the use of

584 microbial transplantation experiments in a single host genotype background.

586 Microbiota plasticity promotes metaorganism acclimation

587 Shifts in the composition of bacterial communities associated with marine animals in

588 response to changes in environmental factors (i.e. temperature, salinity, $\mathrm{pH}$, light 589 exposure, oxygen and $\mathrm{CO} 2$ concentrations, etc.), has been demonstrated in

590 numerous studies ${ }^{18,49-55}$. In some cases these changes in microbiota composition 591 correlated with a higher fitness of acclimated animals ${ }^{53}$, but causal connections are 
592 rare. An experimental replacement of a single bacterium and subsequent

593 demonstration of acquired heat tolerance by the host, was only shown in aphids ${ }^{56}$.

594 To infer if and to what extent the acclimated microbiota confers thermal resistance,

595 we performed transplantation experiments of microbiotas from acclimated animals to

596 non-acclimated ones. These experiments proved that polyps transplanted with the

597 microbiota from animals acclimated at $25^{\circ} \mathrm{C}$, acquired a higher thermal tolerance

598 than those transplanted with the $15^{\circ} \mathrm{C}$ acclimated microbiota. It is important to point

599 out that the animals selected as receivers for this experiment were all clones of the

600 same age, size and shared the same life history, since they came from the same

601 culture box and belonged to the same clonal line as the acclimated donors. With this

602 experimental setup, we were able to disentangle host and microbiota contribution to

603 thermal acclimation and proved that acclimated bacteria can act as heat tolerance

604 promoting bacteria (HTPB).

605 The acclimation of the microbial community is a highly dynamic process that started

606 within the first weeks after environmental shift, and most of the bacterial $\beta$-diversity

607 adjustments happened until 84 woa. Afterwards the microbial community likely

608 reached a stable and homeostatic state. Previous studies on corals ${ }^{57,58}$ detected the

609 presence of a "core microbiota", defined as a cluster of microbial species that are

610 persistent either temporally and/or among different environments or locations, are

611 associated with host-constructed niches, and therefore less sensitive to changes in

612 the surrounding environment. Members of the core microbiota may not necessarily

613 represent the most abundant groups of the community but are hypothesized to exert

614 pivotal functions for the maintenance of the holobiont homeostasis. In contrast, a

615 "dynamic microbiota" exists that varies depending on species, habitat and life stage

616 and is likely a product of stochastic events or a response to changing environmental

617 conditions ${ }^{58}$. Also in $N$. vectensis it seems that during the acclimation process, a

618 core microbiota remained stable in all acclimated polyps, while a more dynamic part

619 of the microbiota changed by either increasing or decreasing in punctual

620 abundances.

621 The increase in $\alpha$-diversity indicates either the acquisition of new bacterial species

622 from the surrounding or a higher evenness in species abundances, where OTUs that

623 were rare at the beginning of the experiment and at lower temperature, became more

624 abundant and therefore detectable. The acquisition of new bacterial species during

625 lab experiments appears unlikely since the polyps are isolated from their natural 
626 environment. Nevertheless, the acclimated animals are not maintained under sterile

627 conditions and thus an exchange of microbial species with the culture medium and

628 from the food supply cannot be excluded. As already pointed out in numerous studies 59-61, higher microbial diversity enhances the ability of the host to respond to

630 environmental stress by providing additional genetic variability, and corals exposed to 631 heat stress exhibit increased microbiota $\beta$-diversity ${ }^{62}$.

632 In addition to the changes in species composition and relative abundances, the 633 associated microbial species can evolve much more rapidly than their multicellular 634 host $^{8}$. Rapidly dividing microbes are predicted to undergo adaptive evolution within 635 weeks to months ${ }^{63}$. Therefore, adaptation of the host can also occur via symbiont 636 acquisition of novel genes ${ }^{64}$, via mutation and/or horizontal gene transfer (HGT) ${ }^{8}$.

637 Therefore, it is possible that, even if a certain bacterial species didn't significantly 638 change in abundance between the different ATs, it may have acquired new functions 639 and adapted to the new conditions within the course of the experiment.

640 Alphaproteobacteria and Gammaproteobacteria constitute main microbial colonizers 641 of corals ${ }^{57,65}$ and of $N$. vectensis ${ }^{18,66}$. The increased thermal tolerance of animals 642 acclimated at high temperatures is often associated with an increase in abundance of 643 these bacterial classes in the associated microbiota ${ }^{67,68}$. In thermally stressed 644 animals, Alphaproteobacteria constitute an important antioxidant army within the 645 coral holobiont ${ }^{69}$ and together with members of the Gammaproteobacteria class, 646 were found to significantly inhibit the growth of coral pathogens (e.g. V. coralliilyticus 647 and $V$. shiloi) ${ }^{7,70}$. They are also known to exert nitrogen fixation in endosymbiosis 648 with marine animals, providing the host with additional nutrient supply ${ }^{71-73}$. In our 649 study, Alphaproteobacteria significantly increased in abundance in the animals 650 acclimated at high temperature and most of the bacterial OTUs significantly 651 overrepresented in the animals transplanted with the $25^{\circ} \mathrm{C}$ acclimated microbiota, 652 belong to the Alpha- and Gammaproteobacteria classes. Among these OTUs, those 653 that could be classified with high confidence, are members of the genera 654 Sulfitobacter, Francisella and Vibrio, and one Flavobacteriia OTU of the genera 655 Muricauda. All these bacterial groups are known to comprise pathogens and 656 symbionts of multicellular organisms ${ }^{74}$. In particular, Sulfitobacter is an 657 endosymbiont of vestimentiferans inhabiting hydrothermal vents, where it performs 658 sulfite oxidation ${ }^{75}$; Francisella is an intracellular pathogen of mammals and various 659 invertebrates and it is supposedly capable of ROS scavenging ${ }^{76,77}$. Members of the 
660 Flavobacteriaceae family are key players in biotransformation and nutrient recycling

661 processes in the marine environment, known intracellular symbionts of insects and 662 intracellular parasites of amoebae ${ }^{78}$. All these characteristics make them good 663 candidates for providing thermal tolerance to the host.

664

665 Changes in host gene expression may confer acclimation

666 Previous studies on Hydra showed that the cnidarian innate immune system actively 667 controls the composition and the homeostasis of the associated microbiota, and that 668 such associations are both species-specific and life-stage specific ${ }^{79-82}$. In corals, it 669 has been shown that unacclimated individuals expressed stronger immune and 670 cellular apoptotic responses than acclimated ones, and disease-related metabolic 671 pathways were significantly enhanced in the former ${ }^{42}$. Moreover, the immune system 672 is sensitive to environmental change ${ }^{59}$ and colonization by beneficial symbionts 673 might lead to the suppression of the host immune response ${ }^{55}$. Elements of the innate 674 immune system, including several members of the interleukin signaling cascades and 675 the transcription factor NF-kB, have been characterized in $N$. vectensis and are 676 hypothesised to play similar roles as their vertebrata homologs ${ }^{15,83-85}$. We 677 hypothesise that the lower expression of genes involved in the innate immune 678 response, plus a positive regulation of the NF-kB signaling observed in the animals 679 acclimated to the higher ATs, indicates a general suppression of the host's immune 680 response. Animals challenged by unfavourable environmental conditions (high 681 temperature in this case), may suppress their immune reaction to favour the 682 establishment of new symbionts. Interestingly, a GO term comprising genes 683 implicated in viral processes, were also upregulated in the animals acclimated at $68415^{\circ} \mathrm{C}$, suggesting a possible higher susceptibility of these animals to infections and a 685 possible implication to their lower viability.

686 On the other hand, steroids and secosteroids from gorgonian and soft corals, have 687 been shown to have antimicrobial and antifouling activity ${ }^{86,87}$ and ${ }^{88}$ found in, $N$. 688 vectensis, homologs of genes involved in steroids metabolism in other animals. The 689 upregulation of genes involved in steroid biosynthesis and metabolism in the high 690 ATs animals may indicate a role in chemical defence against pathogens. In addition, 691 it might hint to the contribution of steroid signalling in the regulation of phenotypic 692 plasticity ${ }^{89,90}$, e.g. in body size regulation and reproduction rate in response to 693 different temperatures. 
694 The enhanced production of small RNAs (sRNAs) in the high ATs acclimated

695 animals, and the high regulation of processes involved in chromatin remodelling in

696 the $15^{\circ} \mathrm{C}$ acclimated animals, suggest a general high gene transcription and

697 translation regulations at these two extreme, not optimal, conditions. Chromatin

698 remodelling processes are implicated in epigenetic modifications and thus possibly

699 inheritable by the offspring ${ }^{91}$. A recent publications ${ }^{92}$ analyzed coral-associated

700 bacteria proteomes and detected potential host epigenome-modifying proteins in the

701 coral microbiota. This, in concert with specific symbionts inheritance, may constitute

702 an additional mechanism for thermal resistance transmission along generations and

703 may explain the significantly higher viability of the $25^{\circ} \mathrm{C}$ acclimated animals' offspring.

704

705 Acquired thermal tolerance is transmitted to the next generation

706 The capacity of a species to survive and adapt to unfavourable environmental

707 conditions does not only rely on the adaptability of the adults but also on the survival

708 of the early life stages. Even if the adults are able to acclimate to periodic heat waves

709 and seasonal temperature increases, their offspring may have a much narrower

710 tolerance range ${ }^{22,93-95}$. It is evident that offspring of marine species, including fishes,

711 mussels, echinoderms and corals can acclimatize to warming and acidifying oceans

712 via transgenerational plasticity (TGP) ${ }^{96-103}$. Both transmission of epigenetic

713 modifications ${ }^{101,104-108}$ and microbiota-mediated transgenerational acclimatization

714 (MMTA) ${ }^{8,40}$ may be involved in the process.

715 Recently, it was shown in $N$. vectensis that animals acclimated to high temperature

716 transmit thermal resistance to their offspring ${ }^{109}$. In our experiments, we moved a

717 step forward by exploring the contribution that the microbiota may have in the

718 inheritability of this plasticity. We fertilized oocytes of acclimated females with sperm

719 of a single male in order to keep the genetic variability as low as possible, and

720 cultured the offspring in a full factorial design at $15^{\circ} \mathrm{C}, 20^{\circ} \mathrm{C}$ and $25^{\circ} \mathrm{C}$. As expected,

721 offspring originated from mothers acclimated at $25^{\circ} \mathrm{C}$ showed the highest survival

722 rate. These results confirmed that polyps acclimated to high temperatures, transmit

723 their acquired thermal tolerance to their offspring, increasing their fitness at high

724 temperature. The fact that offspring from genetically identical mothers show

725 differences in survival rate, indicates either (i) the vertical transmission of HTPB or (ii)

726 the transmission of epigenetic modifications. 
727 For many marine invertebrates, vertical transmission of microbial symbionts are 728 assumed ${ }^{110-113}$. In particular, species that undertake internal fertilization and brood 729 larvae, tend to preferably transmit their symbionts vertically, whereas broadcast 730 spawners and species that rely on external fertilization are thought to mainly acquire 731 their symbionts horizontally ${ }^{114-116}$. Bacteria may also be transmitted to the gametes 732 by incorporation into the mucus that surrounds oocyte and sperm bundles ${ }^{117-119}$. 733 Alternatively, the gametes may acquire bacteria immediately after release by 734 horizontal transmission through water, which contains bacteria released by the 735 parents ${ }^{55}$. A recent publication showed that $N$. vectensis adopts a mixed mode of 736 symbionts transmission to the next generation, consisting of a differential vertical 737 transmission from male and female parent polyps, plus an horizontal acquisition from 738 the surrounding medium during development ${ }^{19}$. Consistently, the results of this study suggest the vertical transmission of HTPB.

740

\section{Acclimated microbiota-a source for assisted evolution}

742 Microbial engineering (ME) is nowadays regularly applied to agriculture and medicine

743 to improve crop yields and human health ${ }^{120}$. Pioneering theoretical works, including 744 the Coral Probiotic Hypothesis ${ }^{7}$ and the Beneficial Microorganisms for Corals (BMC) 745 concept ${ }^{121}$, suggested that artificial selection on the microbiota could improve host 746 fitness over time frames short enough to cope with the actual and future rates of

747 climate changes. Some studies have started ME on corals as a 748 restoration/consenvation option for coral reefs subjected to environmental stresses $7499^{122-124}$. Recently, was showed that corals subjected to experimental warming, 750 inoculated with consortia of potentially beneficial bacteria, bleached less compared to 751 corals that received no probiotics ${ }^{125}$. It needs to be pointed out that MMTA is of 752 pivotal interest because it would be a suitable target for manipulations in perspective 753 of future assisted evolution (AE) programs ${ }^{40,125}$.

754 In this study we proved that long-term acclimation induces enormous changes in the 755 physiology, ecology and even morphology of genetically identical animals; that 756 animals exposed to high (sublethal) temperatures can acclimate and resist to heat 757 stress and that this resistance can be transmitted to the next generations and to non758 acclimated animals by microbiota transplantation. We have been able to detect 759 specific bacterial groups that could be responsible for providing different thermal 
bioRxiv preprint doi: https://doi.org/10.1101/2021.10.18.464790; this version posted October 19, 2021. The copyright holder for this preprint (which was not certified by peer review) is the author/funder, who has granted bioRxiv a license to display the preprint in perpetuity. It is made available under aCC-BY-NC-ND 4.0 International license.

760 tolerances to their host and that may represent good candidates for future assisted-

761 evolution experiments.

762 


\section{Acknowledgments}

764 This work was supported by the Human Frontier Science Program (Young

765 Investigators' Grant RGY0079/2016 and the DFG CRC grant 1182 "Origin and

766 Function of Metaorganisms" (Project B1).

767

768 Conflict of Interest statement

769 The authors declare no conflict of interest.

770

771 Supporting information file is available online.

772 


\section{References}

1. Bay, R. A. \& Palumbi, S. R. Rapid Acclimation Ability Mediated by Transcriptome Changes in Reef-Building Corals. doi:10.1093/gbe/evv085.

2. SR Palumbi, D. B., N. Traylor-Knowles, RA Bay, Palumbi, S. R., Barshis, D. J., Traylor-Knowles, N. \& Bay, R. A. Mechanisms of reef coral resistance to future climate change. Science 344, 895898 (2014).

3. Macklin, M. T. Symbionticism and the Origin of Species. Can. Med. Assoc. J. 17, 498 (1927).

4. Bang, C. et al. Metaorganisms in extreme environments: do microbes play a role in organismal adaptation? Zoology 127, 1-19 (2018).

5. Fraune, S., Forêt, S. \& Reitzel, A. M. Using Nematostella vectensis to Study the Interactions between Genome, Epigenome, and Bacteria in a Changing Environment. Front. Mar. Sci. 3, 1-8 (2016).

6. Kolodny, O. \& Schulenburg, H. Opinion piece Microbiome-mediated plasticity directs host evolution along several distinct time scales. (2020) doi:10.1098/rstb.2019.0589.

7. Reshef, L., Koren, O., Loya, Y., Zilber-Rosenberg, I. \& Rosenberg, E. The Coral Probiotic Hypothesis. Environ. Microbiol. 8, 2068-2073 (2006).

8. Webster, N. S. \& Reusch, T. B. H. Microbial contributions to the persistence of coral reefs. ISME J. 11, 2167-2174 (2017).

9. Totton, A. K. The British Sea Anemones. Nature 135, 977-978 (1935).

10. Hand, C. \& Uhlinger, K. R. The Unique, Widely Distributed, Estuarine Sea Anemone, Nematostella vectensis Stephenson: A Review, New Facts, and Questions. Estuaries 17, 501501 (1994).

11. Darling, J. A., Reitzel, A. M. \& Finnerty, J. R. Regional population structure of a widely introduced estuarine invertebrate: Nematostella vectensis Stephenson in New England. Mol. Ecol. 13, 2969-2981 (2004).

12. Darling, J. A. et al. Rising starlet: The starlet sea anemone, Nematostella vectensis. BioEssays 27, 211-221 (2005).

13. Hand, C. \& Uhlinger, K. R. The culture, sexual and asexual reproduction, and growth of the sea anemone Nematostella vectensis. Biol. Bull. 182, 169-176 (1992).

14. Pearson, C. V. M., Rogers, A. D. \& Sheader, M. The genetic structure of the rare lagoonal sea anemone, Nematostella vectensis Stephenson (Cnidaria; Anthozoa) in the United Kingdom based on RAPD analysis. Mol. Ecol. 11, 2285-2293 (2002).

15. Reitzel, A. M., Darling, J. A., Sullivan, J. C. \& Finnerty, J. R. Global population genetic structure of the starlet anemone Nematostella vectensis: Multiple introductions and implications for conservation policy. Biol. Invasions 10, 1197-1213 (2008).

16. Stefanik, D. J., Friedman, L. E. \& Finnerty, J. R. Collecting, rearing, spawning and inducing regeneration of the starlet sea anemone, Nematostella vectensis. Nat. Protoc. 8, 916-923 (2013).

17. Fritzenwanker, J. H. \& Technau, U. Induction of gametogenesis in the basal cnidarian Nematostella vectensis (Anthozoa). Dev. Genes Evol. 212, 99-103 (2002).

18. Mortzfeld, B. M. et al. Response of bacterial colonization in Nematostella vectensis to development, environment and biogeography. Environ. Microbiol. 18, 1764-1781 (2016).

19. Baldassarre, L. et al. Contribution of maternal and paternal transmission to bacterial colonization in Nematostella vectensis. Front. Microbiol. (in press) doi:10.3389/fmicb.2021.726795.

20. Domin, H. et al. Predicted bacterial interactions affect in vivo microbial colonization dynamics in Nematostella. Front. Microbiol. 9, (2018).

21. Fraune, S. et al. Bacteria-bacteria interactions within the microbiota of the ancestral metazoan Hydra contribute to fungal resistance. ISME J. 9, 1543-1556 (2015).

22. Reitzel, A. M. et al. Physiological and developmental responses to temperature by the sea anemone Nematostella vectensis. Mar. Ecol. Prog. Ser. 484, 115-130 (2013).

23. Fadrosh, D. W. et al. An improved dual-indexing approach for multiplexed 16S rRNA gene sequencing on the Illumina MiSeq platform. Microbiome 2, 6 (2014).

24. Rausch, P. et al. Analysis of factors contributing to variation in the C57BL/6J fecal microbiota across German animal facilities. Int. J. Med. Microbiol. 306, 343-355 (2016).

25. Caporaso, J. G. et al. QIIME allows analysis of high-throughput community sequencing data. Nat. Methods 7, 335-336 (2010).

26. Faith, J. J. et al. The long-term stability of the human gut microbiota. Science 341, 12374391237439 (2013).

27. Segata, N. et al. Metagenomic biomarker discovery and explanation. Genome Biol. 12, R60-R60 (2011). 
834 28. Bolger, A. M., Lohse, M. \& Usadel, B. Trimmomatic: A flexible trimmer for Illumina sequence

data. Bioinformatics 30, 2114-2120 (2014).

29. Kim, D., Langmead, B. \& Salzberg, S. L. HISAT: A fast spliced aligner with low memory requirements. Nat. Methods 12, 357-360 (2015).

30. Pertea, M. et al. StringTie enables improved reconstruction of a transcriptome from RNA-seq reads. Nat. Biotechnol. 33, 290-295 (2015).

31. Shao, M. \& Kingsford, C. accurate assembly of transcripts through phase-preserving graph decomposition. Nat. Biotechnol. 35, 1167-1169 (2017).

32. Niknafs, Y. S., Pandian, B., lyer, H. K., Chinnaiyan, A. M. \& lyer, M. K. TACO produces robust multisample transcriptome assemblies from RNA-seq. Nat. Methods 14, 68-70 (2016).

33. Pertea, M. \& Pertea, G. GFF Utilities: GffRead and GffCompare. F1000Research 9, 304-304 (2020).

34. Waterhouse, R. M. et al. BUSCO applications from quality assessments to gene prediction and phylogenomics. Mol. Biol. Evol. 35, 543-548 (2018).

35. Liao, Y., Smyth, G. K. \& Shi, W. FeatureCounts: An efficient general purpose program for assigning sequence reads to genomic features. Bioinformatics 30, 923-930 (2014).

36. Love, M. I., Huber, W. \& Anders, S. Moderated estimation of fold change and dispersion for RNA-seq data with DESeq2. Genome Biol. 15, 550-550 (2014).

37. Law, C. W., Chen, Y., Shi, W. \& Smyth, G. K. Voom: Precision weights unlock linear model analysis tools for RNA-seq read counts. Genome Biol. 15, R29-R29 (2014).

38. Guest, J. J. R. et al. Contrasting patterns of coral bleaching susceptibility in 2010 suggest an adaptive response to thermal stress. PLoS ONE 7, e33353-e33353 (2012).

39. Puisay, A., Pilon, R., Goiran, C. \& Hédouin, L. Thermal resistances and acclimation potential during coral larval ontogeny in Acropora pulchra. Mar. Environ. Res. 135, 1-10 (2018).

40. MJH Oppen, J. O., HM Putnam, RD Gates, Van Oppen, M. J. H., Oliver, J. K., Putnam, H. M. \& Gates, R. D. Building coral reef resilience through assisted evolution. 112, 2313 (2015).

41. Torda, G. et al. Rapid adaptive responses to climate change in corals. Nat. Clim. Change 7, 627-636 (2017).

42. $\mathrm{Yu}, \mathrm{X}$. et al. Thermal acclimation increases heat tolerance of the scleractinian coral Acropora pruinosa. 733, 139319-139319 (2020).

43. Jury, C. P. \& Toonen, R. J. Adaptive responses and local stressor mitigation drive coral resilience in warmer, more acidic oceans. Proc. R. Soc. B Biol. Sci. 286, 20190614-20190614 (2019).

44. Sully, S., Burkepile, D. E., Donovan, M. K., Hodgson, G. \& van Woesik, R. A global analysis of coral bleaching over the past two decades. Nat. Commun. 10, 5 (2019).

45. Thomas, L. et al. Mechanisms of Thermal Tolerance in Reef-Building Corals across a FineGrained Environmental Mosaic: Lessons from Ofu, American Samoa. Front. Mar. Sci. 4, 434 (2018).

46. Oliver, T. A. \& Palumbi, S. R. Many corals host thermally resistant symbionts in hightemperature habitat. Coral Reefs 30, 241-250 (2011).

47. Kenkel, C. D. \& Matz, M. V. Gene expression plasticity as a mechanism of coral adaptation to a variable environment. Nat. Ecol. Evol. 1, (2017).

48. Barker, V. Exceptional Thermal Tolerance of Coral Reefs in American Samoa a Review. Curr. Clim. Change Rep. 4, 427 (2018).

49. Bourne, D. et al. Changes in coral-associated microbial communities during a bleaching event. 2, 350-363 (2008).

50. Carrier, T. J. \& Reitzel, A. M. The hologenome across environments and the implications of a host-associated microbial repertoire. Front. Microbiol. 8, (2017).

51. Koren, O. \& Rosenberg, E. Bacteria associated with mucus and tissues of the coral Oculina patagonica in summer and winter. Appl. Environ. Microbiol. 72, 5254-5259 (2006).

52. Littman, R., Willis, B. L., Bourne, D. G. \& R Littman, B. W., DG Bourne. Metagenomic analysis of the coral holobiont during a natural bleaching event on the Great Barrier Reef. 3, 651-660 (2011).

53. M Ziegler, F. S., LK Yum, SR Palumbi, CR Voolstra et al. Bacterial community dynamics are linked to patterns of coral heat tolerance. Nat Commun 8, 14213-14213 (2017).

54. Thurber, R. V. et al. Metagenomic analysis of stressed coral holobionts. Environ. Microbiol. 11, 2148-2163 (2009).

55. van Oppen, M. J. H. \& Blackall, L. L. Coral microbiome dynamics, functions and design in a changing world. Nat. Rev. Microbiol. 17, 557-567 (2019).

56. Moran, N. A. \& Yun, Y. Experimental replacement of an obligate insect symbiont. Proc. Natl. Acad. Sci. U. S. A. 112, 2093-2096 (2015). 
895

896

897

898

899

900

901

902

903

904

905

906

907

908

909

910

911

912

913

914

915

916

917

918

919

920

921

922

923

924

925

926

927

928

929

930

931

932

933

934

935

936

937

938

939

940

941

942

943

944

945

946

947

948

949

950

951

952

953

954

955

57. Ainsworth, T. D. T. et al. The coral core microbiome identifies rare bacterial taxa as ubiquitous endosymbionts. ISME J 9, 2261-2274 (2015).

58. Hester, E. R., Barott, K. L., Nulton, J., Vermeij, M. J. A. \& Rohwer, F. L. Stable and sporadic symbiotic communities of coral and algal holobionts. ISME J. 10, 1157-1169 (2016).

59. Bourne, D. G., Morrow, K. M. \& Webster, N. S. Insights into the Coral Microbiome: Underpinning the Health and Resilience of Reef Ecosystems. Annu. Rev. Microbiol. 70, 340 (2016).

60. Pollock, F. J. et al. Reduced diversity and stability of coral-associated bacterial communities and suppressed immune function precedes disease onset in corals. R. Soc. Open Sci. 6, (2019).

61. Zilber-Rosenberg, I. \& Rosenberg, E. Role of microorganisms in the evolution of animals and plants: The hologenome theory of evolution. FEMS Microbiol. Rev. 32, 723-735 (2008).

62. Zaneveld, J. R., McMinds, R., Thurber, R. V. \& JR Zaneveld, R. M., RV Thurber. Stress and stability: Applying the Anna Karenina principle to animal microbiomes. Nat. Microbiol. 2, 1712117121 (2017).

63. Elena, S. F. \& Lenski, R. E. Evolution experiments with microorganisms: The dynamics and genetic bases of adaptation. Nat. Rev. Genet. 4, 457-469 (2003).

64. Hehemann, J. H. et al. Transfer of carbohydrate-active enzymes from marine bacteria to Japanese gut microbiota. Nature 464, 908-912 (2010).

65. Bourne, D. G. Microbiological assessment of a disease outbreak on corals from Magnetic Island (Great Barrier Reef, Australia). Coral Reefs 24, 304-312 (2005).

66. Leach, W. B., Carrier, T. J. \& Reitzel, A. M. Diel patterning in the bacterial community associated with the sea anemone Nematostella vectensis. Ecol. Evol. 9, 9935-9947 (2019).

67. Pootakham, W. et al. Heat-induced shift in coral microbiome reveals several members of the Rhodobacteraceae family as indicator species for thermal stress in Porites lutea. MicrobiologyOpen 8, (2019).

68. Webster, N. Host-associated coral reef microbes respond to the cumulative pressures of ocean warming and ocean acidification. Sci Rep 6, (2016).

69. Van, K. L., Ae, A., Schupp, P. \& Slattery, M. The distribution of dimethylsulfoniopropionate in tropical Pacific coral reef invertebrates. doi:10.1007/s00338-006-0114-9.

70. Rypien, K. L., Ward, J. R. \& Azam, F. Antagonistic interactions among coral-associated bacteria. Environ. Microbiol. 12, 28-39 (2010).

71. Blazejak, A., Erséus, C., Amann, R. \& Dubilier, N. Coexistence of bacterial sulfide oxidizers, sulfate reducers, and spirochetes in a gutless worm (oligochaeta) from the Peru margin. Appl. Environ. Microbiol. 71, 1553-1561 (2005).

72. Dubilier, N. et al. Phylogenetic diversity of bacterial endosymbionts in the gutless marine oligochete Olavius loisae (Annelida). Mar. Ecol. Prog. Ser. 178, 271-280 (1999).

73. Rincón-Rosales, R., Lloret, L., Ponce, E. \& Martínez-Romero, E. Erratum: Rhizobia with different symbiotic efficiencies nodulate Acaciella angustissima in Mexico, including Sinorhizobium chiapanecum sp. nov. which has common symbiotic genes with Sinorhizobium mexicanum (FEMS Microbiology Ecology (2009) 67 (103-117)). FEMS Microbiol. Ecol. 68, 255-255 (2009).

74. Rosenberg, E. \& DeLong, E. F., Stackebrandt, E. ,. Lory, S. ,. Thompson, F. The Prokaryotes Prokaryotic Biology and Symbiotic / Eugene Rosenberg / Springer. (2013).

75. Kimura, H., Higashide, Y. \& Naganuma, T. Endosymbiotic Microflora of the Vestimentiferan Tubeworm (Lamellibrachia sp.) from a Bathyal Cold Seep. Mar. Biotechnol. 5, 593-603 (2003).

76. Melillo, A. A., Bakshi, C. S. \& Melendez, J. A. Francisella tularensis antioxidants harness reactive oxygen species to restrict macrophage signaling and cytokine production. J. Biol. Chem. 285, 27553-27560 (2010).

77. Rabadi, S. M. et al. Antioxidant defenses of Francisella tularensis modulate macrophage function and production of proinflammatory cytokines. J. Biol. Chem. 291, 5009-5021 (2016).

78. McBride, M. J. The family flavobacteriaceae. in The Prokaryotes: Other Major Lineages of Bacteria and The Archaea vol. 9783642389542 643-676 (Springer-Verlag Berlin Heidelberg, 2014).

79. Augustin, R., Fraune, S. \& Bosch, T. C. G. How Hydra senses and destroys microbes. Semin. Immunol. 22, 54-58 (2010).

80. Augustin, R. et al. A secreted antibacterial neuropeptide shapes the microbiome of Hydra. Nat. Commun. 8, (2017).

81. Franzenburg, S. et al. Distinct antimicrobial peptide expression determines host species-specific bacterial associations. Proc. Natl. Acad. Sci. 110, E3730-E3738 (2013).

82. Fraune, S., Abe, Y. \& Bosch, T. C. G. G. Disturbing epithelial homeostasis in the metazoan Hydra leads to drastic changes in associated microbiota. Environ. Microbiol. 11, 2361-9 (2009).

83. Brennan, J. J. et al. Sea anemone model has a single Toll-like receptor that can function in pathogen detection, NF-KB signal transduction, and development. 114, E10122-E10131 (2017). 
956

957

958

959

960

961

962

963

964

965

966

967

968

969

970

971

972

973

974

975

976

977

978

979

980

981

982

983

984

985

986

987

988

989

990

991

992

993

994

995

996

997

998

999

1000

1001

1002

1003

1004

1005

1006

1007

1008

1009

1010

1011

1012

1013

1014

1015

1016

84. Sullivan, J. C. et al. Two alleles of NF-KB in the sea anemone Nematostella vectensis are widely dispersed in nature and encode proteins with distinct activities. PLOS ONE 4, (2009).

85. Wolenski, F. S. et al. Characterization of the Core Elements of the NF- B Signaling Pathway of the Sea Anemone Nematostella vectensis. Mol. Cell. Biol. 31, 1076-1087 (2011).

86. Qi, S. H., Zhang, S., Yang, L. H. \& Qian, P. Y. Antifouling and antibacterial compounds from the gorgonians Subergorgia suberosa and Scripearia gracillis. Nat. Prod. Res. 22, 154-166 (2008).

87. Sica, D. \& Musumeci, D. Secosteroids of marine origin. Steroids 69, 743-756 (2004).

88. Tarrant, A. M. et al. Steroid metabolism in cnidarians: Insights from Nematostella vectensis. Mol. Cell. Endocrinol. 301, 27-36 (2009).

89. Gáliková, M., Klepsatel, P., Senti, G. \& Flatt, T. Steroid hormone regulation of C. elegans and Drosophila aging and life history. Exp. Gerontol. 46, 141-147 (2011).

90. Taubenheim, J., Kortmann, C. \& Fraune, S. Function and Evolution of Nuclear Receptors in Environmental-Dependent Postembryonic Development. Front. Cell Dev. Biol. 9, 653792 (2021).

91. Becker, P. B. \& Workman, J. L. Nucleosome remodeling and epigenetics. Cold Spring Harb. Perspect. Biol. 5, a017905-a017905 (2013).

92. Barno, A. R., Villela, H. D. M., Aranda, M., Thomas, T. \& Peixoto, R. S. Host under epigenetic control: A novel perspective on the interaction between microorganisms and corals. BioEssays n/a, 2100068.

93. Chua, C. M., Leggat, W., Moya, A. \& Baird, A. H. Temperature affects the early life history stages of corals more than near future ocean acidification. Mar. Ecol. Prog. Ser. 475, 85-92 (2013).

94. Ericson, J. A. et al. Combined effects of two ocean change stressors, warming and acidification, on fertilization and early development of the Antarctic echinoid Sterechinus neumayeri. Polar Biol. 35, 1027-1034 (2012).

95. Sheppard Brennand, H., Soars, N., Dworjanyn, S. A., Davis, A. R. \& Byrne, M. Impact of ocean warming and ocean acidification on larval development and calcification in the sea urchin Tripneustes gratilla. PLOS ONE 5, (2010).

96. Bernal, M. A. et al. Phenotypic and molecular consequences of stepwise temperature increase across generations in a coral reef fish. Mol. Ecol. 27, 4516-4528 (2018).

97. Clark, M. S. et al. Molecular mechanisms underpinning transgenerational plasticity in the green sea urchin Psammechinus miliaris. Sci. Rep. 9, 1-12 (2019).

98. JM Donelson, P. M., MI McCormick, CR Pitcher, Donelson, J. M., Munday, P. L., McCormick, M. I. \& Pitcher, C. R. Rapid transgenerational acclimation of a tropical reef fish to climate change. 2 , 30-32 (2012).

99. Miller, G. M., Watson, S. A., Donelson, J. M., McCormick, M. I. \& Munday, P. L. Parental environment mediates impacts of increased carbon dioxide on a coral reef fish. Nat. Clim. Change 2, 858-861 (2012).

100. Munday, P. L. Transgenerational acclimation of fishes to climate change and ocean acidification. F1000Prime Rep. 6, 99-99 (2014).

101. Ryu, T. et al. An Epigenetic Signature for Within-Generational Plasticity of a Reef Fish to Ocean Warming. Front. Mar. Sci. 7, (2020).

102. Veilleux, H. D. H. et al. Molecular processes of transgenerational acclimation to a warming ocean. 5, 1074-1078 (2015).

103. Zhao, C. et al. Transgenerational effects of ocean warming on the sea urchin Strongylocentrotus intermedius. Ecotoxicol. Environ. Saf. 151, 212-219 (2018).

104. Eirin-Lopez, J. M. \& Putnam, H. M. Marine Environmental Epigenetics. Annu. Rev. Mar. Sci. 11, 335-368 (2019).

105. Fallet, M., Luquet, E., David, P. \& Cosseau, C. Epigenetic inheritance and intergenerational effects in mollusks. Gene 729, 144166-144166 (2020).

106. HM Putnam, R. G. Preconditioning in the reef-building coral Pocillopora damicornis and the potential for trans-generational acclimatization in coral larvae under future climate change conditions. J Exp Biol 218, 2365-2372 (2015).

107. L Daxinger, E. W. Transgenerational epigenetic inheritance: more questions than answers. Genome Res 20, 1623-1628 (2010).

108. Ptashne, M. Epigenetics: core misconcept. Proc Natl Acad Sci USA 110, 7101-7103 (2013).

109. Rivera, H. E., Chen, C.-Y., Gibson, M. C. \& Tarrant, A. M. Plasticity in parental effects confers rapid larval thermal tolerance in the estuarine anemone Nematostella vectensis. J. Exp. Biol. (2021) doi:10.1242/jeb.236745.

110. Hirose, E. \& Fukuda, T. Vertical transmission of photosymbionts in the colonial ascidian Didemnum molle: The larval tunic prevents symbionts from attaching to the anterior part of larvae. Zoolog. Sci. 23, 669-674 (2006). 
1017

1018

1019

1020

1021

1022

1023

1024

1025

1026

1027

1028

1029

1030

1031

1032

1033

1034

1035

1036

1037

1038

1039

1040

1041

1042

1043

1044

1045

1046

1047

1048

1049

1050

1051

1052

111. JL Padilla-Gamiño, X. P., C. Bird, GT Concepcion, RD Gates. From parent to gamete: vertical transmission of Symbiodinium (Dinophyceae) ITS2 sequence assemblages in the reef building coral Montipora capitata. PLoS One 7, e38440-e38440 (2012).

112. Sharp, K. H., Eam, B., John Faulkner, D. \& Haygood, M. G. Vertical transmission of diverse microbes in the tropical sponge Corticium sp. Appl. Environ. Microbiol. 73, 622-629 (2007).

113. Sipkema, D. et al. Similar sponge-associated bacteria can be acquired via both vertical and horizontal transmission. Environ. Microbiol. 17, 3807-3821 (2015).

114. Apprill, A., Marlow, H. Q., Martindale, M. Q. \& Rappé, M. S. The onset of microbial associations in the coral Pocillopora meandrina. ISME J. 3, 685-699 (2009).

115. Sharp, K. H., Distel, D., Paul, V. J. \& KH Sharp, D. D., VJ Paul. Diversity and dynamics of bacterial communities in early life stages of the Caribbean coral Porites astreoides. ISME J. 6, 790-801 (2012).

116. Lesser, M. P., Stat, M. \& Gates, R. D. The endosymbiotic dinoflagellates (Symbiodinium sp.) of corals are parasites and mutualists. Coral Reefs 32, 603-611 (2013).

117. Ceh, J., Raina, J. B., Soo, R. M., van Keulen, M. \& Bourne, D. G. Coral-bacterial communities before and after a coral mass spawning event on Ningaloo Reef. PLOS ONE 7, (2012).

118. Ricardo, G. F., Jones, R. J., Negri, A. P. \& Stocker, R. That sinking feeling: suspended sediments can prevent the ascent of coral egg bundles. Sci Rep 6, (2016).

119. Leite, D. C. A. D. et al. Broadcast spawning coral Mussismilia Hispida can vertically transfer its associated bacterial core. 8, 176-176 (2017).

120. Epstein, H. E. et al. Microbiome engineering: enhancing climate resilience in corals. Front. Ecol. Environ. 17, 108 (2019).

121. Peixoto, R. S., Rosado, P. M., Leite, D. C. de A., Rosado, A. S. \& Bourne, D. G. Beneficial microorganisms for corals (BMC) Proposed mechanisms for coral health and resilience. Front. Microbiol. 8, 341 (2017).

122. Chakravarti, L. J., Beltran, V. H. \& van Oppen, M. J. H. Rapid thermal adaptation in photosymbionts of reef-building corals. Glob. Change Biol. 23, 4675-4688 (2017).

123. Damjanovic, K., Blackall, L. L., Webster, N. S. \& van Oppen, M. J. H. H. The contribution of microbial biotechnology to mitigating coral reef degradation. Microb. Biotechnol. 10, 1236-1243 (2017).

124. Damjanovic, K., Van Oppen, M. J. H., Menéndez, P. \& Blackall, L. L. Experimental Inoculation of Coral Recruits With Marine Bacteria Indicates Scope for Microbiome Manipulation in Acropora tenuis and Platygyra daedalea. Front. Microbiol. 10, (2019).

125. Rosado, P. M. et al. Marine probiotics: increasing coral resistance to bleaching through microbiome manipulation. ISME J. 13, 921-936 (2019). 